\title{
LÍMITES A LA POTESTAD TRIBUTARIA Y LA CARGA TRIBUTARIA EN BRASIL*
}

LIMITATIONS ON THE POWER OF TAXATION AND THE TAX BURDEN IN BRAZIL LIMITATION A LA POUVOIR DE TAXATION ET LA CHARGE FISCALE AU BRÉSIL

\author{
Rodrigo Caramori Petry ${ }^{* *}$
}

\begin{abstract}
RESUMEN
En el presente trabajo se analizan los fundamentos constitucionales y los limites fundamentales de la potestad tributaria en Brasil, señalando los diferentes principios y normas de la Constitución de Brasil en materia tributaria. El texto también presenta la estructura de los diferentes impuestos brasileños, de modo que el lector pueda tener una idea general acerca de la composición de la carga tributaria en este pais.
\end{abstract}

Palabras Clave: Derecho Tributario Brasil - Derecho Constitucional - Sistema tributario - Impuestos - Carga fiscal

ABSTRACT

This article examines the constitutional foundations and the fundamental limits of the power to tax in Brazil, pointing to the different principles and rules of the Brazilian Constitution on tax matters. The text also presents the structure of the different Brazilian taxes, so that the reader can get a general idea about the composition of the tax burden in Brazil.

KEYWORDS: Tax law Brazil - Constitutional Law -Tax system - Taxes - Tax burden

RÉSUMÉ

Il s'agit d'analyser le fondement constitutionnel et les limites fondamentales du pouvoir de l'État détablir des impôts au Brésil et souligne les principes et règles de la Constitution brésilienne en matière fiscale. Le texte présente également la structure des différents impôts au Brésil, de sorte que le lecteur puisse se faire une idée générale de la composition de la charge fiscale dans ce pays.

MOTS CLÉS: Le droit fiscal Brésil - Droit constitutionnel - Système fiscal - Impôts - Charge fiscale

\section{INTRODUCCIÓN}

Este artículo tiene como objetivo presentar los fundamentos constitucionales y la forma de organización del sistema tributario brasileño, señalando los límites de la potestad tributaria en Brasil, los diferentes tipos de recaudación de impuestos, para ofrecer una visión completa de la formación de la carga tributaria brasileña.

\footnotetext{
*Artículo recibido el 14 de octubre de 2013 y aceptado para su publicación el 26 de mayo de 2014.

** Abogado y Consultor en los Estados de Paraná (Curitiba) y São Paulo (São Paulo), Brasil. Doctorando en Derecho Económico, Financiero y Tributario por la Universidad de São Paulo (USP), Brasil. Miembro Asociado del Instituto Brasileño de Derecho Tributario (IBDT). Maestre en Derecho Económico y Social por la Pontificia Universidad Católica de Paraná (PUC-PR), Brasil. Profesor de Derecho Tributario.
} 


\section{El RÉGIMEN POLÍTICO TERRITORIAL BRASILEÑO Y LA DisTRIBUCIÓN DE COMPETENCIAS Y DE INGRESOS TRIBUTARIOS}

Brasil es un país organizado bajo el régimen político republicano presidencialista, en forma de Estado federativo con el poder dividido en los estados, en el que la competencia para instituir y cobrar tributos está repartida, no solamente entre el poder central (federal) y los 26 entes federados ("Estados", unidades federativas), sino también dividida entre 5.570 poderes locales, denominados municipalidades, que son subdivisiones político territoriales de los estados ${ }^{1}$. Además, otra entidad político territorial, llamada distrito federal (DF), donde se localiza la sede de la República Federativa de Brasil, también recibe competencia tributaria, pudiendo instituir y cobrar los tributos típicos de los estados y también los asignados a las municipalidades ${ }^{2}$. Esta organización está establecida por la Constitución de la República Federativa de Brasil, promulgada en 1988 y todavía en vigor (hasta hoy modificada por 87 enmiendas) $)^{3}$.

Además de la competencia para instituir y cobrar tributos ser distribuida entre las entidades políticas (gobierno central, estados, DF y municipalidades), también la hacienda recaudada con la cobranza de los principales impuestos se distribuye entre ellos mediante transferencias (repasses). Así, el gobierno central, federal, está obligado por la Constitución a repasar una parte de los valores recaudados con sus principales impuestos a los estados, DF y a las municipalidades; así como los estados deben repasar una parte del rendimiento de sus principales impuestos a las municipalidades.

Pero la repartición de los valores recaudados entre los entes políticos no ocurre sólo con los impuestos, pues también una parte de los tributos recaudados con contribuciones especiales de seguridad social (especialmente las que financian la salud pública y la asistencia social) y una reducida cuota de las contribuciones de intervención en el dominio económico (especialmente en el sector de combustibles) está distribuida entre el gobierno federal, estados, DF y municipalidades ${ }^{4}$. Para verificar las reglas de distribución del monto de la recaudación tributaria en

\footnotetext{
${ }^{1}$ Mayores informaciones sobre las municipalidades de Brasil están disponibles en el sitio web del Instituto Brasileiro de Geografia e Estatística (IBGE) en la dirección: <http://www.ibge.gov.br> [Consulta: 21 abril 2013].

${ }^{2}$ Esta es la razón por la que el distrito federal es conocido en Brasil como un tipo de "Estado diferenciado", pues acumula la competencia tributaria de Estado y de municipio.

${ }^{3}$ El texto actualizado de la Constitución brasileña, así como de las 87 enmiendas (hasta hoy han sido editadas 6 enmiendas de revisión, promulgadas en 1994, y 81 enmiendas ordinarias más, pueden ser consultados en el sitio de la Presidencia de la República en Internet, disponible en <http://www.planalto. gov.br/ccivil_03/Constituicao/Constituicao.htm> [Consulta: 26 agosto 2013].

${ }^{4}$ Es interesante observar que la doctrina brasileña, casi al unísono, afirma repetidamente que el recaudado por el gobierno federal con la cobranza de contribuciones especiales no está repartida con los demás entes políticos (estados, DF y municipalidades). Eso no es totalmente cierto, como hemos visto aquí.
} 
Brasil, véanse los artículos 157 a 162, así como los artículos 198, \$3º, II, de la Constitución brasileña.

\section{La Constitución Federal de 1988 (CF/1988) y el Código Tributario Nacional (CTN)}

La Constitución brasileña está especialmente detallada en materia tributaria, constituyendo un sistema amplio de normas de protección de los ciudadanos contribuyentes. Además del texto constitucional brasileño poseer un capítulo especialmente dedicado a la tributación, conteniendo la división de las competencias tributarias entre los entes políticos federados y la fijación de principios y límites al poder de tributar, existen numerosas otras normas tributarias esparcidas por el texto constitucional. Por tanto, existen normas dirigidas a la tributación en todos los capítulos de la Constitución brasileña, aunque algunas no sean expresas, pero implícitas, derivadas de la interpretación de normas generales de la Constitución cuando son aplicadas en materia tributaria.

Por tal razón, decimos que el ciudadano brasileño posee un régimen de especial protección constitucional en materia tributaria, caso singular en el mundo, pues no encontramos en la Constitución de otros países representativos el mismo tratamiento expreso y detallado relativo a la actividad tributaria del estado5.

Debajo de la Constitución Federal, actuando como una interfaz entre ella y la legislación ordinaria de los entes políticos (gobierno federal estados, DF y municipalidades), está el Código Tributario Nacional (Ley No 5.172/1966), que, por fuerza de la recepción constitucional en 1988, posee status de ley complementaria con normas generales en materia de legislación tributaria, cumpliendo el previsto en el artículo 146 de la Constitución ${ }^{6}$.

\section{LOS PRINCIPALES LÍMITES CONSTITUCIONALES AL PODER DE TRIBUTAR EN BRASIL}

Las normas fundamentales del sistema jurídico tributario brasileño son conducidas por la Constitución Federal y sus enmiendas, y sirven como límites al poder de tributar, pudiendo ser subdivididas en: normas de competencia tributaria, normas de inmunidad tributaria, derechos fundamentales tributarios, principios tributarios, principios económicos tributarios, postulados, y normas de otra naturaleza.

${ }^{5}$ Petry, Rodrigo Caramori (2014). "Direito constitucional tributário comparado: A tributação nas Constituiçóes do Brasil e de outros países”. Revista Direito Tributário Atual, No 30, São Paulo: Dialética e Instituto Brasileiro de Direito Tributário (IBDT), p. 358.

${ }^{6}$ Petry, Rodrigo Caramori (2010). "Reflexões sobre a estrutura do direito tributário no Brasil”. Revista Direito Tributário Atual, No 24, São Paulo: Dialética e Instituto Brasileiro de Direito Tributário (IBDT), p. 505. 


\subsection{Normas de competencia tributaria}

Las normas de competencia tributaria ejercen la función de autorizar a los entes políticos (gobierno federal, estados, DF y municipalidades) la institución de los tributos y de las demás normas involucradas con la actividad tributaria (reglamentación, cálculo del tributo, contabilización por la autoridad, sanciones por el incumplimiento, fiscalización, etc.).

\subsection{Normas de inmunidad tributaria}

Las normas de inmunidad tributaria ejercen la función de prohibir la institución de tributos sobre ciertos hechos, actividades, bienes o personas, representando casi siempre un favoritismo o una garantía a la preservación de ciertos valores, principios y derechos fundamentales de los brasileños. Es con tal visión que la Constitución prevé, entre otros casos, la inmunidad del patrimonio, de la renta y de servicios de los propios entes políticos, estando libres de impuestos; así como la inmunidad de libros, de entidades religiosas, de partidos políticos y de entidades de educación sin fines lucrativos.

\subsection{Derechos fundamentales tributarios}

Además de esas normas, existen en la Constitución diversas normas definidoras de derechos fundamentales de los ciudadanos contribuyentes ${ }^{7}$ en Brasil y que así ejercen la función de indicar límites elementales a la actividad tributaria. Así destacan: derecho a la libertad, a la igualdad, a la propiedad y a la seguridad jurídica; derecho a la inviolabilidad de la intimidad y vida privada; derecho a la inviolabilidad del sigilo de la correspondencia y de las comunicaciones privadas, etc.

\subsection{Principios tributarios (normas principiológicas)}

Las normas que fijan principios, sean ellos generales o especialmente tributarios, son normas con alto grado de abstracción y generalidad, que dan directrices para un Estado ideal de cosas que expresa los valores fundamentales del orden jurídico, y así orientan la construcción y la interpretación de las demás normas. Algunas reglas constitucionales, a pesar de tener contenido directo y aplicación inmediata, también son llamadas de "principios" cuando poseen elevada importancia en el sistema jurídico.

Los principios tributarios en Brasil más importantes son los siguientes:

i) Principio de la legalidad tributaria: posee 6 dimensiones, veámoslas a continuación:

\footnotetext{
${ }^{7}$ Compréndanse aquí las personas físicas y jurídicas, recordando que incluso las empresas (personas jurídicas) sujetas a las normas tributarias son formadas, en última instancia, por personas físicas.
} 
- Legalidad tributaria estricta (artículo 150, I, de la CF): exige que la institución o aumento del tributo se haga por ley, en la cual deben describirse todos los elementos básicos del tributo (hecho generador, sujeto activo, sujeto pasivo, base de cálculo, alícuota u otro elemento cuantificador). Se admiten raras excepciones, como en el caso de las alícuotas de los impuestos de importación y exportación, del impuesto sobre productos industrializados, y del impuesto sobre operaciones financieras, seguros, cambio, y con títulos y acciones de empresas, tributos esos que pueden ser alterados por el Poder Ejecutivo, por medio de un decreto u otro acto administrativo, pero dentro de ciertos límites.

- Legalidad tributaria exentaria (implícita en la CF): exige que la reducción o extinción de un tributo sea hecha por ley.

- Legalidad tributaria general (artículo 5, I, de la CF): exige que las demás relaciones jurídicas tributarias, o sea, las que interesan para la tributación pero que no corresponden a la institución del tributo en sí, tengan fundamento en la ley, pero sin exigir que su contenido sea descrito en la misma. La legalidad general tributaria es la exigida en el caso de ser instituidos deberes documentales al contribuyente, en el interés de la fiscalización, como, por ejemplo, la exigencia del contribuyente de emitir notas de gastos comprobando las ventas de mercancías, o la exigencia de rellenar y entregar declaraciones de sus bienes. Aquí la ley autoriza la institución de los deberes, dejando a la Administración tributaria definir, por medio de reglamentos, el contenido de esos deberes, o su formato/formularios/modos, etc.

- Legalidad tributaria administrativa (artículo 37, caput, de la CF): exige que el cálculo y contabilización del tributo por el agente público sean fijados en la ley.

- Legalidad tributaria sancionadora, que se divide en administrativa (artículo 37, caput) y criminal (artículo 5ㅇ, XXXIX): exige que la previsión de infracciones y la determinación de las sanciones respectivas sean hechas con base en la ley.

- Legalidad tributaria procesal, que se divide en administrativa (artículos 37, caput y $5^{\circ}$, LIV) y judicial (artículo $5^{\circ}$, LIV), expresión del due process of law, exige que las reglas del proceso administrativo y del judicial estén previstas en ley, dando oportunidad al contribuyente de conocer, con seguridad, en qué condiciones podrá litigar con el estado aplicador de tributos.

ii) Principio de la anterioridad de la ley (artículos 150, III, “b” y “c”, y 195, \$60): exige que transcurra un plazo antes del inicio de la vigencia de la ley que instituya o aumente un tributo, contado tal plazo a partir de la publicación, para que el contribuyente pueda prepararse para el encargo. Algunos tributos son excepciones de la regla, con vigencia inmediata ${ }^{8}$. La regla constitucional posee tres especies:

- Anterioridad como exigencia de, como mínimo, 90 días y lo que falte para exceder el ejercicio financiero en el que ocurrió la publicación de la ley;

${ }^{8}$ Petry, Rodrigo Caramori (2009a). "O princípio da anterioridade da lei tributária: teoria geral e análise de casos”. Revista Dialética de Direito Tributário, No 170, São Paulo: Dialética, pp. 75-92. 
- Anterioridad como exigencia de que el inicio de la vigencia de la ley ocurra sólo en el inicio del ejercicio financiero siguiente al de la publicación;

- Anterioridad como exigencia de 90 días para inicio de la vigencia de la ley.

iii) Principio de la irretroactividad de la ley tributaria (artículo 150, III, "a", de la CF): exige que la ley que instituya o aumente un tributo sea aplicada a los hechos posteriores a su entrada en vigor, y nunca a hechos anteriores. Es una forma de garantizar la seguridad jurídica. Ese principio-regla es absoluto, o sea, se aplica a todos los tributos en Brasil.

iv) Principio de la isonomía tributaria (artículo 150, I, de la CF): prohíbe que la ley instituya tratamiento desigual entre contribuyentes que estén en situación equivalente. Son exigidas por la Constitución brasileña tres clases de isonomía tributaria:

- Igualdad ante la ley (artículo 5º, de la CF): exigencia de que la ley sea hipotética y de aplicación general, sin particularizar contribuyentes;

- Igualdad en la ley (artículo 150, II, de la CF): exige que la ley use criterios constitucionales y coherentes para diferenciar el tratamiento tributario entre los contribuyentes;

- Igualdad en la forma de participación en el coste de la seguridad social (artículo 194, V, de la CF): exigencia de que la ley equilibre las alícuotas y las bases de cálculo de las contribuciones entre los diversos sectores económicos, de forma que todos contribuyan de forma igualitaria, para un justo financiamiento de los servicios públicos de salud, seguridad y asistencia social.

v) Principio de la capacidad contributiva: exige que, siempre que sea posible, el estado brasileño instituya tributos sobre hechos que manifiesten riqueza de los contribuyentes, y distribuya una mayor carga tributaria para los que tengan mayores condiciones de contribuir, reservando siempre un mínimo vital fuera de tributación. Es derivado del principio de la justicia (artículo $3^{\circ}, \mathrm{I}, \mathrm{CF}$ ) y posee cuatro formas de manifestación, aplicables conforme la clase de tributo son las siguientes:

- Capacidad contributiva objetiva (implícito): los tributos deben tener, por regla, un hecho generador que manifieste una forma de riqueza del contribuyente.

- Capacidad contributiva como respeto al mínimo vital (implícito): es una exigencia de respeto a la dignidad de la persona humana, por la cual el tributo no puede alcanzar un patrón patrimonial mínimo del contribuyente.

- Capacidad contributiva subjetiva (artículo $145, \$ 1^{\circ}$, de la CF): aplicable a los impuestos, mediante uso de dos técnicas: la progresividad fiscal de alícuotas, aplicada principalmente en el caso de impuestos personales (impuesto de renta o sobre grandes fortunas); y la técnica de la selectividad de alícuotas para mercancías, productos o bienes, aplicada a los impuestos sobre circulación/consumo o impuestos sobre la propiedad de inmuebles y vehículos.

- Capacidad contributiva relacionada al costo o al beneficio del contribuyente (implícito): quien debe pagar más es quien más causa gastos públicos, o quien más recibe beneficios y servicios públicos por parte del Estado, es aplicable principalmente a las contribuciones que financian la seguridad social. 
vi) Principio de la prohibición al tributo con efecto de confisco (artículo 150, IV): exige que los tributos o multas tributarias no agoten la manifestación de riqueza o el patrimonio del contribuyente. El confisco está autorizado (artículo 5ㅇ, XLV y XLVI) sólo como sanción material (pena de pérdida de los bienes), como ocurre en el caso de importaciones prohibidas o con fraude o negación de impuestos.

vii) Principio federativo tributario (implícito): exige que las personas políticas de la federación brasileña (gobierno federal, estados, DF y municipalidades) se traten de forma equilibrada e isonómica, sin favorecimientos. El principio implica:

- Prohibición al gobierno federal, estados, DF y municipalidades de establecer limitación al tráfico de personas o bienes entre ellos, por medio de tributos (artículo 152);

- Prohibición al gobierno federal de instituir tributos que no sean uniformes entre los contribuyentes de los estados, del DF y de las municipalidades, admitiendo apenas los incentivos fiscales para regiones menos favorecidas del país (artículo 151, I);

- Prohibición al gobierno federal de crear exenciones o reducciones de tributos de los estados, del DF o de las municipalidades (artículo 151, III);

- Prohibición a los estados y a las municipalidades de instituir diferencias tributarias fundamentadas en el origen o en el destino de los bienes o servicios sujetos a impuestos estatales o municipales (artículo 152 de la CF).

\subsection{Reglas técnicas de aplicación de principios tributarios}

Para que algunos principios puedan ser utilizados en la práctica de la tributación, la Constitución señala reglas técnicas de aplicación, específicas para algunos tributos, principalmente los impuestos sobre renta, patrimonio y circulación de bienes. Son las técnicas tributarias de la no cumulatividad, de la selectividad y de la progresividad.

i) No cumulatividad tributaria (artículos $153, \$ 3^{\circ}$, II; 154, I; $155, \$ 2^{\circ}$, I; 195, $\$ 4 ; 195, \S 12$ ): realiza los fundamentos de la Orden Económica Brasileña, basada en la garantía e incentivo del desarrollo económico y libre competencia. Es una técnica aplicada en tributos sobre circulación económica, o sea, que por su naturaleza inciden en más de una fase de las cadenas económicas de circulación de bienes/mercancías o de servicios y que, por eso, pueden causar excesivo aumento de los precios, con el consiguiente desincentivo al consumo y a la producción económica. La técnica exige que el valor del tributo cobrado en una etapa u operación sea compensado con el valor que fue pagado en la etapa anterior de circulación del bien/mercancía/servicio, tributándose, en la práctica, sólo el valor económico que sea agregado en cada etapa.

ii) Selectividad tributaria (artículos $153, \$ 3^{\circ}, \mathrm{I} ; 155, \$ 2^{\circ}$, III e $\$ 6^{\circ}$, II; $156, \$ 1^{\circ}$, II): realiza o hace efectivo el principio de la capacidad contributiva y el principio de la isonomía, aunque de modo indirecto, además de poder servir a objetivos 
extrafiscales relacionados a políticas públicas. Es una técnica aplicada en impuestos sobre circulación económica (impuestos sobre la venta de mercancías, productos o servicios) e impuestos sobre patrimonio (impuestos sobre la propiedad de inmuebles y vehículos automotores). La técnica permite fijar alícuotas diferentes entre los contribuyentes, conforme a los siguientes criterios:

- Esencialidad (un criterio que, en la práctica, es aplicado en las leyes sólo parcialmente, debe diferenciar lo que es superfluo/lujo de lo que es esencial para la vida del contribuyente) - para mercancías, productos o servicios;

- Localización o forma de uso (comercial o residencial) - para inmuebles;

- Tipo o forma de uso (empresarial o personal) - para automóviles.

iii) Progresividad tributaria (artículos $145, \$ 1^{\circ} ; 153, \$ 2^{\circ}, \mathrm{I}$ y $\$ 4^{\circ}, \mathrm{I} ; 156, \$ 1^{\circ}$, I): realiza o hace efectivo el principio de la capacidad contributiva (en su dimensión subjetiva), además de poder servir a objetivos extrafiscales/políticos públicos. Es una técnica aplicada en impuestos sobre la renta, grandes fortunas, y la propiedad de inmuebles. La técnica permite fijar alícuotas crecientes (progresivas) conforme los siguientes criterios:

- Crecimiento del valor de la base de cálculo/riqueza tributable;

- Criterio constitucional extrafiscal (estímulo a la reforma agraria, directrices de urbanización de las ciudades o función social de la propiedad inmueble).

\subsection{Principios económico tributarios}

Son los principios que están en la parte de la Constitución de Brasil que trata de la Orden Económica y poseen especial aplicación como limitadores de la actividad tributaria debido a la economía. Son los siguientes, extraídos del artículo 170 de la Constitución:

i) Respeto a la libre iniciativa empresarial y profesional.

ii) Respeto a la propiedad privada y estímulo a la función social de la propiedad.

iii) Preservación de la libre competencia entre las empresas y profesionales.

iv) Defensa del consumidor, recordando que los tributos influencian los precios.

v) Defensa del medio ambiente, inclusive mediante estímulos tributarios conforme el impacto ambiental de ciertas actividades económicas.

vi) Reducción de las desigualdades regionales y sociales.

vii) Busca del pleno empleo de los trabajadores.

viii) Tratamiento simplificado y favorecido para pequeñas empresas.

\subsection{Postulados de aplicación}

Para permitir una aplicación adecuada, los principios y reglas tributarios necesitan postulados (implícitos en la Constitución), reconocidos por la jurisprudencia brasileña, por medio de los cuales sean evaluados los límites de la interpretación. 
Son ellos, especialmente: i) racionabilidad; ii) proporcionalidad; iii) prohibición de exceso. Exigen que las reglas y principios tributarios sean necesarios, suficientes, coherentes, no limiten derechos en exceso y sean adecuados al fin al que se destinan?.

\subsection{Normas tributarias de otra naturaleza}

Además de las normas constitucionales anteriormente enumeradas, también encontramos en el texto de la Constitución brasileña diversas otras normas que, por no encajarse en ninguna de las modalidades anteriores, son llamadas "normas tributarias de otra naturaleza”. Esas normas son, en su mayoría, identificadas en tres tipos:

i) Normas que regulan derechos específicos de los contribuyentes, como por ejemplo, el $\$ 5^{\circ}$ del artículo 150 de la Constitución ${ }^{10}$.

ii) Normas que son simples desdoblamientos de las normas anteriores (especialmente de los principios tributarios).

iii) Normas que son principios o reglas específicos para un determinado tributo (por ejemplo, el principio de la universalidad del impuesto a la renta).

\section{LOS TRIBUTOS EN BRASIL ${ }^{11}$}

\subsection{Impuestos}

Impuesto es un tipo de tributo que tiene por hecho generador una manifestación de riqueza, o sea, hecho económico independiente de una actuación estatal dirigida al contribuyente. La Constitución de Brasil autoriza el gobierno federal, estados, DF y municipalidades a instituir impuestos sobre diversas manifestaciones de riqueza, distribuyendo la competencia conforme la materia tributable/hecho

\footnotetext{
${ }^{9}$ Para un estudio más profundo del tema: Ávila, Humberto (2009). Teoria dos princípios: da definição à aplicação dos princípios jurídicos. São Paulo: Malheiros, $9^{a}$ edição.

${ }^{10}$ Artículo 150. “(...) $\$ 5^{\circ}$ A lei determinará medidas para que os consumidores sejam esclarecidos acerca dos impostos que incidam sobre mercadorias e serviços". (Art. 150. “(...) $\$ 5^{\circ}$ La ley determinará medidas para que se les aclare a los consumidores acerca de los impuestos que incidan sobre mercancías y servicios"). En Brasil se hicieron comunes las protestas y las campañas por informaciones más precisas y por una divulgación más amplia acerca de la carga tributaria brasileña, o sea, del onus directo e indirecto que los tributos generan sobre los contribuyentes de modo general. Los alardeados récord de recaudación del Fisco Federal, constantes en los últimos años, reavivaron los movimientos populares que desean mayor transparencia fiscal, y la presión ejercida por sectores organizados de la sociedad acabó resultando en la aprobación y promulgación de la Ley No 12.741/2012, que reglamenta la regla del $\$ 5^{\circ}$ del artículo 150 de la Constitución. A pesar de crear un onus más organizacional y documental a los empresarios, ya sobrecargados con muchos otros deberes fiscales, la nueva ley es positiva en el sentido de proporcionar mayor concientización de la carga tributaria, aunque la información no comprenda todos los tributos incidentes en la actividad empresarial y que repercuten en los precios.

${ }^{11}$ Petry, Rodrigo Caramori (2013a). "Análise jurídica da carga tributária brasileira”. Revista de Estudos Tributários, No 93, São Paulo: IOB/Síntese e Instituto de Estudos Tributários (IET), septiembre-octubre/2013, pp. 81-117.
} 
generador. Para procurar evitar conflictos de competencia entre los entes políticos, cabe a la ley complementaria definir reglas generales sobre los hechos generadores, bases de cálculo y contribuyentes de los impuestos (conforme determina el artículo 146, I y III, “a”, de la CF). Ese papel es cumplido por el Código Tributario Nacional (CTN) y por algunas leyes complementarias.

\subsubsection{Impuestos del gobierno federal}

\section{a) Impuesto sobre la importación de productos extranjeros - II (artículo 153, I, de la CF)}

- Legislación básica: artículos 19 a 22 del CTN y Decreto-Ley No 37/1966, reglamentado por el Decreto No 6.759/2009 (Reglamento Aduanero).

- Hecho generador: entrada de bienes corpóreos ${ }^{12}$ en el territorio brasileño, incluyéndose aquí el equipaje del viajero que entre en Brasil, cuando supere la cuota de US\$ 500,00 (vía aérea o marítima) o US\$ 300,00 (vía terrestre o fluvial). El CTN también prevé como hecho generador el remate en subasta de bienes aprehendidos en la aduana, pero tal hipótesis no es sancionada por la ley actual específica del impuesto.

- Sujeto activo: gobierno federal (Secretaría de la Hacienda Federal de Brasil).

- Sujeto pasivo: el importador, pero puede ser responsable del pago del tributo el transportador de la mercancía/bien, entre otros indicados por ley.

- Base de cálculo: valor aduanero de la importación (conforme Acuerdo General de Tarifas y Comercio del GATT, firmado en el ámbito de la Organización Mundial del Comercio) ${ }^{13}$.

- Alícuotas: varían entre el 0\% al 20\% en general ${ }^{14}$ conforme "Tarifa Externa Común” del MERCOSUR ${ }^{15}$ (pudiendo, excepcionalmente, alcanzar hasta el 35\%

\footnotetext{
${ }^{12}$ La referencia de la CF la "importación de productos” comprende mercancías y otros bienes no comerciales.

${ }^{13}$ Incluyendo valor de las mercancías, el costo de transporte, carga/descarga y seguro, véanse reglas del GATT, de ahí llamar la base de cálculo aquí de "valor de la importación CIF" (Cost, Insurance and Freight). El valor en moneda extranjera (US\$) es convertido en REAL (R\$) conforme cambio del día inmediatamente anterior al de la operación de exportación, en la cotización indicada por el Ministerio de la Hacienda de Brasil.

${ }^{14} \mathrm{La}$ TEC varía sólo en múltiplos de 2 . Así las alícuotas son pares: $2 \%, 4 \%, 6 \%$, etc., mientras las excepciones a la tabla (ítems "ex tarifarios" permitidos) pueden tener alícuotas impares (v. gr. 35\%).

${ }^{15}$ La TEC es una tabla con aproximadamente 400 páginas, con una lista de mercancías y alícuotas respectivas, que sigue un patrón llamado Nomenclatura Común del MERCOSUR. La TEC fue adoptada en 1995 con base en el Tratado Internacional del Mercado Común del Sur de 1991 (comprende Brasil, Argentina, Uruguay, Paraguay y Venezuela, el penúltimo prohibido temporalmente de decisiones, y el último país insertado en el bloque en 2012), estandarizando la tributación de las importaciones oriundas de países fuera del Bloque (lo que se denomina "uno aduanera"), mientras se busca no tributar el comercio entre los países del Bloque (lo que se denomina "libre comercio"). Cada país puede instituir un $20 \%$ de ítems excepcionados de la TEC (llamados "ex tarifarios") cada 6 meses, para permitir ajustes en la política económica, además de restricciones a importaciones extra bloque o incluso entre bloque.
} 
en el caso de productos industrializados o el 55\% para productos agrícolas) ${ }^{16}$, el $50 \%$ en el caso de exceso de equipaje de viajero, y el 60\% para importación en remesa postal o expresa (Correos o Courier). El Poder Ejecutivo puede alterar las alícuotas, en los límites dados por la legislación que flexibiliza la TEC, negociados en el MERCOSUR y OMC ${ }^{17}$.

- Otros aspectos: la legislación prevé beneficios fiscales (v. gr. exención del impuesto) para importación de bienes de interés nacional (instituciones científicas, educacionales, asistenciales, etc.) e importaciones temporales (inclusive $d r a w b a c k)^{18}$.

- Destinación del valor recaudado: arcas del gobierno federal, para gastos generales presupuestarios. El impuesto auxilia en el control del comercio extranjero, con fuerte función extrafiscal.

\section{b) Impuesto sobre la exportación de productos - IE (artículo 153, II, de la CF)}

- Legislación básica: artículos 23 a 28 del CTN y Decreto-Ley No 1.578/1977, reglamentado por el Decreto No 6.759/2009 (Reglamento Aduanero).

- Hecho generador: salida, del territorio brasileño, de bienes corpóreos nacionales o nacionalizados, sean mercancías o incluso bienes fuera del comercio.

- Sujeto activo: gobierno federal (Secretaría de la Hacienda Federal de Brasil).

- Sujeto pasivo: el exportador (persona física o jurídica que promueve la salida).

- Base de cálculo: valor o precio de mercado del producto objeto de exportación ${ }^{19}$.

- Alícuotas: varían entre el 0\% al 150\% en general. Aunque la alícuota standard legal sea de $30 \%$, la casi totalidad de los productos brasileños es exenta o tiene alícuota $0 \%$, puesto que no le interesa a Brasil gravar sus productos en la exportación.

\footnotetext{
${ }^{16}$ Por decisión del Consejo del MERCOSUR, se puede adoptar una alícuota mayor que el 20\% en casos específicos para ex tarifarios (excepciones a la TEC), hasta los límites del 35\% y el 55\% permitidos por la Organización Mundial del Comercio (OMC). Para mayores informaciones, véanse: <www.mercosul.gov. br> y <www.desenvolvimento.gov.br> [Consulta: 21 abril 2013].

${ }^{17}$ El Acuerdo MERCOSUL prevé excepciones a la TEC, y con base en esa apertura Brasil puede firmar acuerdos internacionales de libre comercio con países fuera del Bloque (fijando exención, alícuota $0 \%$ o reducción del impuesto de importación), como ocurre entre Brasil y México, por ejemplo, por medio del Acuerdo de Cooperación Económica N 53 firmado en 2002 y renegociado desde entonces, incluso con versión para el sector automotor (ACE No 55), sector que es el más expresivo en el comercio bilateral Brasil-México.

${ }^{18}$ Régimen que beneficia la importación de insumos, materias primas, embalajes, para fabricación en Brasil de productos destinados a posterior exportación, como estímulo fiscal.

${ }^{19}$ El valor en moneda extranjera (US\$) se convierte en REAL (R\$) conforme cambio del día inmediatamente anterior al de la operación de exportación, en la cotización indicada por el Ministerio de la Hacienda de Brasil. La base de cálculo es diferente de la aplicada al impuesto de importación, pues no están incluidos los costos con flete, carga/descarga y seguro, por ello se habla en "valor de exportación FOB” (free on board).
} 
- Otros aspectos: una parte de la exportación de fuego/municiones y la exportación de tabaco/cigarrillos son tributadas con la alícuota máxima $(150 \%)^{20}$.

- Destinación de los rendimientos: arcas del gobierno federal, para constituir reservas monetarias (control cambiario para estabilidad de la moneda nacional). El impuesto es instrumento de control monetario y del comercio extranjero, con fuerte función extrafiscal.

\section{c) Impuesto sobre la renta y rendimientos de cualquier naturaleza - IR (artículo 153, III, CF)}

- Legislación básica: artículos 43 a 45 del CTN y numerosas leyes, consolidadas por el Decreto No 3.000/1999 (Reglamento del Impuesto a la Renta - RIR).

- Hecho generador: renta producto del capital y/o del trabajo (sueldos, ingresos diversos, lucros empresariales, rendimientos de aplicaciones financieras, etc.)

- Sujeto activo: gobierno federal (Secretaría de la Hacienda Federal del Brasil).

- Sujeto pasivo: personas físicas (IRPF) o personas jurídicas (IRPJ) en general.

- Base de cálculo

- Personas físicas: Es la renta anual (del 1 de enero al 31 de diciembre), resultado de los ingresos obtenidos deducidos de ciertos gastos (dependientes/hijos, educación, médicos, gastos de los profesionales autónomos, etc.). El contribuyente apura y anticipa algunos recogimientos mensuales, y en otros casos las fuentes pagadoras descuentan el impuesto, como en el caso de los empleadores que descuentan el impuesto del sueldo bruto de los empleados. Terminado el año, la renta efectiva es determinada y declarada en el mes de abril del año subsiguiente, cuando puede ser determinado el valor a restituir (caso en que el impuesto adelantado durante el año haya sido mayor que lo debido), el valor a pagar (cuando el ajuste demuestre que todavía se debe algún valor de impuesto por el contribuyente). Algunos ingresos poseen tributación específica.

- Personas jurídicas con fines lucrativos y empresariales: hay tres formas de cálculo, en las que el lucro puede ser presumido, real, o arbitrado, dentro de un período de tiempo de cálculo anual (con adelantos mensuales) o trimestral. Y en determinados negocios, se hace una retención del valor del impuesto por la fuente de la renta, con alícuota reducida (el 1\% o el 1,5\% a título de anticipación del impuesto).

i) Lucro Presumido: es un régimen opcional, para las empresas con hacienda de hasta US\$ 24 millones $^{21}$ al año ${ }^{22}$, por el cual la base de cálculo del impuesto

\footnotetext{
${ }^{20}$ Brasil es uno de los mayores exportadores de armas ligeras del mundo (5 lugar), y a pesar de la alícuota del $150 \%$, gran parte de sus exportaciones de armas no está tributada por el impuesto de exportación. Brasil es el mayor exportador de tabaco y cigarrillos del mundo (a pesar de no ser el mayor productor).

${ }^{21}$ El dólar americano aquí sirve sólo como una referencia didáctica, y está estimado en el cambio de R \$2,00 (a pesar de que su cotización ya haya alcanzado R \$2,25 en junio/2013).

${ }^{22}$ La Ley 12.814/2013 prevé que ese límite será ampliado para $\mathrm{R} \$ 72$ millones/año a partir del 1 de enero de 2014.
} 
es un porcentual de las haciendas obtenidas en la actividad de la empresa, que sirve como presunción legal del lucro tributable ${ }^{23}$. El cálculo del lucro y pago del impuesto es trimestral. Es una forma opcional simplificada de cálculo del impuesto.

ii) Lucro Real: es el régimen general de las empresa, es obligatorio para instituciones financieras/bancos, empresas con renta o lucros obtenidos en el extranjero ${ }^{24} \mathrm{y}$ empresas que reciban beneficios fiscales especiales. La base de cálculo del impuesto es el valor efectivo/real del lucro tributable, resultado de la diferencia entre los ingresos brutos de las ventas, servicios, ingresos financieros, etc., y el valor de los costos y gastos necesarios al mantenimiento de la actividad de la empresa. Tal base se ajusta después por algunas adiciones, exclusiones y compensaciones de valores, previstas en la ley. El cálculo y pago del impuesto puede ser trimestral, o anual (en este caso con anticipación mensual en base presumida ${ }^{25}$, que puede ser suspendida o reducida en caso que se encuentre perjuicio). El perjuicio de período anterior puede compensar/ reducir hasta un $30 \%$ del lucro posterior.

iii) Lucro Arbitrado: en el caso que la empresa no posea contabilidad regular para recaudar el impuesto, la Autoridad Fiscal puede arbitrar el lucro, usando criterios legales: el lucro es presumido, como en el régimen de lucro presumido, acrecido en un $20 \%{ }^{26}$; o el lucro es arbitrado con base en porcentuales sobre determinadas grandezas económicas conocidas de la empresa e identificadas por la Autoridad fiscal ${ }^{27}$. En caso que falten elementos para el cálculo normal, pero sea conocido el valor de rendimiento bruto, la propia empresa puede recaudar su impuesto por las reglas del arbitraje.

- Personas jurídicas sin fines lucrativos: son exentas o inmunes al impuesto.

- Alícuotas

\footnotetext{
${ }^{23}$ Son cuatro tipos de base, o sea, porcentajes de lucro presumido: el 1,6\% (reventa de combustibles); el 8\% (comercio, industria y servicios específicos); el 16\% (servicio de transporte de personas) y el 32\% (servicios en general, intermediación de negocios y administración o locación de bienes). Las empresas prestadoras de servicios de menor porte económico, o sea, que obtengan rendimiento bruto de hasta US\$ 60.000,00/ año, pueden tener como lucro presumido sólo el $6 \%$ de su rendimiento al revés del 32\%.

${ }^{24}$ Excepto las empresas de exportación de mercancías/servicios a personas no vinculadas en el extranjero.

${ }^{25}$ Los mismos porcentajes aplicados en el régimen de apuración del Lucro Presumido (bancos tienen lucro presumido del 16\%, y empresas de factoring han estimado el 32\% del rendimiento como presunción de lucro).

${ }^{26}$ Excepto para instituciones financieras, para las cuales el lucro arbitrado corresponde al $45 \%$ de su rendimiento bruto.

${ }^{27}$ El lucro así equivaldrá al: 1,5\% del lucro real anterior; o el 4\% del activo; o el 5\% del patrimonio neto; o el $7 \%$ del capital; o el $40 \%$ de las compras; o el $40 \%$ de la hoja de salarios y de las compras de insumos; o el $80 \%$ de la hoja de salarios de los empleados; o el $90 \%$ del valor del alquiler mensual pagado por la empresa.
} 
- Persona física - rendimientos en general: las alícuotas inciden progresivamente sobre franjas de renta conforme la tabla a continuación, válida para declaración de 2013:

\begin{tabular}{|l|l|c|}
\hline Tabla de alícuotas del impuesto sobre la renta de la persona física en Brasil $(2013 / 2012)^{28}$ \\
\hline Base de cálculo mensual en US $\${ }^{29}$ & Base de cálculo anual en US\$ $\$ 30$ & Alícuota \\
\hline De 0,00 hasta 809,44 & De 0,00 hasta $9.713,38$ & ---- \\
\hline De 809,45 hasta $1.213,10$ & De $9.713,39$ hasta $14.557,23$ & $7,5 \%$ \\
\hline De $1.213,11$ hasta $1.617,49$ & De $14.557,24$ hasta $19.409,91$ & $15 \%$ \\
\hline De $1.617,50$ hasta $2.021,08$ & De $19.409,92$ hasta $24.253,05$ & $22,5 \%$ \\
\hline Superior a $2.021,09$ & Superior a $24.253,05$ & $27,5 \%$ \\
\hline
\end{tabular}

- Persona jurídica/empresa: las alícuotas inciden progresivamente sobre dos franjas de renta, de la forma indicada en la tabla siguiente:

\begin{tabular}{|l|l|c|}
\hline Tabla de alícuotas del impuesto sobre la renta de las empresas en Brasil \\
\hline Base de cálculo mensual en US\$ ${ }^{31}$ & Base de cálculo anual en US $\$^{32}$ & Alícuota \\
\hline De 0,00 hasta $10.000,00$ & De 0,00 hasta $120.000,00$ & $15 \%$ \\
\hline Superior a $10.000,00$ & Superior a $120.000,00$ & $25 \% \%^{33}$ \\
\hline
\end{tabular}

- Alícuotas específicas: para las personas físicas y para las empresas todavía existen algunas otras alícuotas. A continuación destacamos solo los casos más comunes:

\begin{tabular}{|l|l|c|}
\hline \multicolumn{2}{|l|}{ Alícuotas del impuesto sobre la renta en casos específicos en Brasil } \\
\hline Clase de renta/ganancia & Subclase & Alícuota \\
\hline \multirow{2}{*}{$\begin{array}{l}\text { Ganancia de capital/lucro en la } \\
\text { alienación de bienes o derechos }\end{array}$} & $\begin{array}{l}\text { Bienes o derechos con valor menor de } \\
\text { US\$ } 17.374,90^{34} / \text { mes }\end{array}$ & Exento \\
\cline { 2 - 3 } & Bienes de valor igual o superior & $15 \%$ \\
\hline \multirow{2}{*}{$\begin{array}{l}\text { Ingresos en el mercado de } \\
\text { acciones/bolsa de valores }\end{array}$} & $\begin{array}{l}\text { Operaciones con valores iguales o inferiores a } \\
\text { US\$ 9.928,51/mes }\end{array}$ & Exento \\
\cline { 2 - 3 } & Operaciones comunes & $15 \%$ \\
\cline { 2 - 3 } $\begin{array}{l}\text { Pagado a persona/empresa en el } \\
\text { extranjero: Es en general tributado } \\
\text { en la fuente de la renta (Brasil) }\end{array}$ & $\begin{array}{l}\text { Ganancia de capital, servicios técnicos y } \\
\text { royalties }^{35}\end{array}$ & $15 \%$ \\
\cline { 2 - 3 } & Renta de trabajo/servicios en general & $20 \%$ \\
\hline
\end{tabular}

\footnotetext{
${ }^{28}$ La tabla contiene valores válidos para la declaración entregada por los contribuyentes en 2013, en la cual están los datos referentes al año calendario de 2012 (año del hecho generador).

${ }^{29} \mathrm{El}$ valor del Impuesto en Brasil siempre se calcula en moneda brasileña (REAL/R \$). El dólar norteamericano aquí sirve sólo como una referencia didáctica, y está estimado en el cambio de R \$2,00 (junio/2013).

${ }^{30} \mathrm{La}$ base de cálculo anual corresponde a la multiplicación de la base mensual por 12 (meses del año).

${ }^{31}$ El valor del Impuesto en Brasil siempre se calcula en la moneda brasileña (REAL/ R\$). El dólar norteamericano aquí es una referencia didáctica, y está estimado en el cambio de R \$2,00 (a pesar de que en junio/2013 ya haya alcanzado $\mathrm{R} \$ 2,25)$.

${ }^{32}$ La base de cálculo anual corresponde a la multiplicación de la base mensual por 12 (meses del año).

${ }^{33}$ La alícuota del 25\% es resultado de la aplicación de un adicional del 10\% sobre la alícuota básica del 15\%.

${ }^{34}$ El dólar norteamericano aquí es una referencia didáctica, y está estimado en el cambio de R\$ 2,00 (a pesar de que en junio/2013 ya haya alcanzado $\mathrm{R} \$ 2,25)$.
} 


\begin{tabular}{|l|l|c|}
\hline \multicolumn{2}{|l|}{ Alícuotas del impuesto sobre la renta en casos específicos en Brasil } \\
\hline Clase de renta/ganancia & Subclase & Alícuota \\
\hline \multirow{2}{*}{$\begin{array}{l}\text { Ingresos netos en aplicaciones } \\
\text { financieras de renta fija o variable }\end{array}$} & Corto plazo de permanencia de la inversión & $22,5 \%$ \\
\cline { 2 - 3 } (alícuotas decrecientes conforme el & Corto-medio plazo & $20 \%$ \\
\cline { 2 - 3 } \begin{tabular}{l} 
plazo de inversión) $)^{37}$ \\
\cline { 2 - 3 } Premios en efectivo
\end{tabular} & Largo plazo & $17,5 \%$ \\
\hline \multirow{2}{*}{ Predio plazo } & $15 \%$ \\
\cline { 2 - 3 } & Sorteos en general & $30 \%$ \\
\hline
\end{tabular}

- Otros aspectos:

- Exenciones y otros beneficios fiscales: hay casos de exención para personas físicas (v.g. jubilación de enfermos, ingresos en venta del inmueble propio, etc.), exenciones y reducciones de impuesto para empresas como incentivo a la producción, etc., y están exentos los lucros y dividendos recibidos por personas físicas o jurídicas (inclusive extranjeras), en virtud de participación societaria.

- Tratados internacionales: Brasil posee tratados con otros países sobre el impuesto a la renta, con el objetivo de evitar la bitributación de la renta transnacional y combatir la remesa de dinero al extranjero en la forma de distribución disfrazada de lucros en operaciones entre empresas ligadas (multinacionales) ${ }^{38}$.

- Destinación de la hacienda: arcas de la Uno (gastos generales presupuestarios), que debe repasar un 48\%, de la siguiente forma: el 21,5\% para Estados y DF, y el 23,5\% para las Municipalidades, además del 3\% para instituciones financieras públicas, para financiar el desarrollo de las regiones norte, noreste y centroeste de Brasil. El impuesto cobrado sobre la remuneración de los funcionarios públicos de los estados, DF y Municipalidades está dirigido a las arcas de los respectivos gobiernos (artículos 157, I, 158, I y 159, I, de la CF).

\section{d) Impuesto sobre productos industrializados - IPI \\ (artículo 153, IV, de la CF)}

- Legislación básica: artículos 46 a 51 del CTN, Ley No 4.502/1964, DecretoLey No 34/1966 y otras leyes, reglamentadas por el Decreto No 7.212/2010 (Reglamento del IPI).

\footnotetext{
${ }^{35}$ Hay casos específicos: la Convención Internacional Brasil-México en materia de Impuesto a la Renta (Decreto No 6.000/2006) fija alícuota del impuesto brasileño en un $10 \%$ sobre la remesa de royalties de asistencia técnica y semejantes pagos de fuente en Brasil a residentes o con domicilio en México.

${ }^{36} \mathrm{La}$ alícuota del $25 \%$ se exige en cualquier caso de remesa para residente o con domicilio en país con tributación favorecida (aquel país que no tribute o que tribute la renta con alícuota inferior al 20\%).

${ }^{37}$ Con la regresión del impuesto, el gobierno de Brasil quiere incentivar aplicaciones financieras de largo plazo.

${ }^{38}$ Brasil y México firmaron Convención para evitar la Doble Tributación y Prevenir Evasión Fiscal en Relación a los Impuestos Sobre la Renta, firmado en 2003 y en vigor por el Decreto No 6.000/2006.
} 
- Hecho generador: realizar operaciones con productos industrializados, lo que comprende:

i) importación de productos por personas físicas o empresas;

ii) ventas de productos por las industrias o equiparadas (es el caso de la empresa importadora que comercializa los productos importados, o de la empresa comercial que vende productos a las industrias).

El CTN prevé como hecho generador también el remate en subasta del producto confiscado en la aduana, pero esta hipótesis no está efectuada en la ley actual del impuesto, o sea, no incide el impuesto.

- Sujeto activo: Uno Federal (Secretaría de la Hacienda Federal de Brasil).

- Sujeto pasivo:

i) importador persona física ${ }^{39}$ o empresa;

ii) empresa industrial o equiparada (empresa importadora, o empresa comercial que vende productos a las industrias).

Establecimientos de la misma empresa son tratados como contribuyentes diferentes. Pueden ser responsabilizados por el pagado o transportador o almacenador, en caso de falta de documentos fiscales u otras irregularidades.

- Base de cálculo:

i) en el caso de IPI cobrado en la importación, la base es el valor aduanero de la importación (conforme Acuerdo General de Tarifas y Comercio del GATT, firmado en el ámbito de la $\mathrm{OMC})^{40}+$ impuesto de importación + tasas aduaneras y cargos de cambio;

ii) en el IPI cobrado en las ventas, la base es el valor de la operación (valor del producto industrializado + costos de seguro y flete + el valor del impuesto estadual sobre circulación de mercancías (ICMS) que incide en la misma operación). Algunos productos (cigarrillos, etc.) poseen base de cálculo especial para tributación.

- Alícuotas: están dispuestas en la "Tabla de Incidencia del IPI (TIPI)"41 aprobada actualmente por el Decreto No 7.660/2011. En regla, las alícuotas para el IPI-

\footnotetext{
${ }^{39} \mathrm{La}$ persona física que importe producto industrializado para consumo propio puede ser liberada del pago del impuesto, conforme jurisprudencia actual del Supremo Tribunal Federal (1 a Grupo, Ag.Reg. RE No 550.170/SP, Reportero Ministro Ricardo Lewandowski, entre otros). La cuestión será analizada nuevamente en sede de repercusión general en el juicio del RE No 723.651/RS, Reportero Ministro Marco Aurelio.

${ }^{40}$ Incluyendo valor de las mercancías, el costo de transporte, carga/descarga y seguro, véanse reglas del GATT, por ello llamamos la base de cálculo aquí de "valor de la importación CIF" (Cost, Insurance and Freight). El valor en moneda extranjera (US\$) se convierte en REAL (R\$) conforme cambio del día inmediatamente anterior al de la operación de exportación, en la cotización indicada por el Ministerio de Hacienda de Brasil.

${ }^{41}$ La TIPI es una tabla con aproximadamente 400 páginas, y usa la misma nomenclatura y clasificación de mercancías utilizadas por la TEC (tabla de alícuotas del impuesto de importación), o sea, la Nomenclatura Común del MERCOSUR (NCM), razón por la cual constan descritas en la TIPI diversas mercancías que no son productos industrializados, o sea, no pueden ser tributados por el impuesto sobre productos industrializados. Por eso, en el caso de esas mercancías la TIPI no atribuye alícuotas del IPI. Dichas mercancías constan como "no tributadas", y son identificadas por la sigla "NT" insertada en el local donde constaría la alícuota del impuesto. Las alícuotas indicadas en la TIPI son alteradas por el Gobierno de acuerdo con su
} 
ventas son las mismas aplicadas para el IPI-importación, pero pueden ser distintas en algunos casos, para los cuales el Gobierno Federal entienda adecuado por motivo de política fiscal. Las alícuotas deben ser aplicadas selectivamente, siendo mayores o menores conforme la esencialidad del producto para el ciudadano-contribuyente. Tanto en el caso del IPI-ventas como en el IPI-importación, la gran mayoría de los productos tiene alícuotas entre el $0 \%$ y el $20 \%$ (siendo muy comunes alícuotas del $0 \%, 5 \%, 10 \%$ y el 15\%). Los otros productos (bebidas, perfumes, armas, pieles, etc.) son tributados con alícuotas entre el 25\%, 30\%, 40\% hasta el 60\%. $\mathrm{Y}$ algunos productos (bebidas, helado y cigarrillos) poseen un régimen alternativo especial, en el que la alícuota del impuesto puede ser un determinado valor en dinero efectivo, cobrado por unidad o medida ${ }^{42}$.

Específicamente en relación al IPI-importación, el equipaje de viajero está exento, inclusive eventual exceso (que queda sujeto al impuesto de importación a la alícuota del 50\%), así como está exenta la importación en remesa postal o expresa (Correos o Courier).

Conforme autoriza la Constitución (artículo 153, $\$ 1^{\circ}$ ), el Poder Ejecutivo puede alterar las alícuotas del IPI, reduciéndolas hasta el $0 \%$ o aumentando en hasta un 30\% las alícuotas en vigor, desde que el acto sea motivado por exigencia de política económica fiscal, cuando esté en juego el interés del desarrollo o protección de la economía nacional, mantenida la selectividad en función de la esencialidad del producto y el respeto a los tratados internacionales de los cuales Brasil sea signatario (especialmente en el caso de alteraciones del IPI-importación) ${ }^{43}$.

- Otros aspectos

- Cálculo del impuesto: el IPI es un impuesto no cumulativo. El valor del IPI/ ventas debido en un período de cálculo (mensual) es el resultado de dos operacio-

política fiscal del momento, que de tiempos en tiempos reduce o aumenta las alícuotas del impuesto para incentivar o no los sectores industriales estratégicos para la economía.

${ }^{42}$ En la tabla de alícuotas TIPI está prevista una alícuota elevadísima del 300\% para cigarrillos, pero en ese caso la alícuota real/efectiva será del $45 \%$ del valor de la operación de venta del cigarrillo en el comercio al consumidor final, debido a una formulación especial de la base de cálculo en la tributación del cigarrillo (el régimen de IPI para cigarrillos está en el Decreto No 7.555/2011, con base en la Ley No 12.546/2011). Alternativamente, la industria de cigarrillos podrá optar por el cálculo complejo del IPI, en el cual parte del impuesto será calculado mediante aplicación de un porcentaje sobre parte del valor de venta en el comercio al consumidor final y otra parte será correspondiente a un valor en moneda $(\mathrm{R} \$)$ por unidad del producto (en Brasil, la "unidad del producto" aquí corresponde a 1 atado o paquete conteniendo 20 cigarrillos). La mayoría de las industrias de cigarrillo en Brasil opta por ese régimen complejo de tributación. Es importante aún observar que la alta carga en la tributación de los cigarrillos en Brasil encuentra apoyo en la Convención Cuadro para Control del Tabaco, promulgada en 2003, entrando en vigor internacional en 2005 (el primer tratado internacional de salud pública de la historia), firmada entre 192 países miembros de la Organización Mundial de la Salud/ONU, fue internalizado por Brasil por el Decreto No 5.658/2006, tras aprobación por el Congreso Nacional brasileño (Decreto-Legislativo No 1.012/2005).

${ }^{43}$ Dichos límites/justificativas legales para alteración del alícuota del IPI están en el Decreto-Ley No 1.199/1971. 
nes matemáticas: primero se hace la incidencia de la alícuota sobre el valor de las operaciones en el período; y de ese resultado se hace la sustracción/compensación del valor del impuesto debido/pagado en las operaciones anteriores, que funciona como un crédito a rebajar/compensar. En el caso del IPI-importación, el régimen de cálculo es diferente: el impuesto es debido por operación, y por tanto, es independiente de la recaudación mensual del IPI-ventas.

- Beneficios fiscales: la legislación prevé beneficios fiscales (v.g. exención del impuesto) en el caso del IPI-importación (de forma semejante al que ocurre con el impuesto de importación) para productos de interés de la economía o de la sociedad brasileña, además de prever exenciones y reducciones del IPI-ventas internas, para beneficiar el desarrollo industrial brasileño, reduciendo el precio al consumidor y estimulando el consumo de determinados productos, estimulando la economía.

- Sustitución tributaria: la legislación del IPI prevé una forma especial alternativa de tributación para las industrias en ciertos casos: Es la "sustitución tributaria hacia atrás" en la cadena de circulación productiva. En ese caso, la empresa que vende los productos está dispensada de la recaudación del impuesto, que se hace de forma centralizada por la empresa compradora. De otro lado, tenemos en la legislación del IPI también la previsión de "sustitución tributaria delante de la cadena”. Pero, a pesar de ser autorizada, su aplicación al IPI, de hecho, está limitada por dificultades operacionales.

- Destinación de la hacienda: arcas de la Uno (gastos generales presupuestarios), que debe repasar el $58 \%$ de la siguiente forma: el 29\% (21,5\% + 7,5\%) a los estados y DF, y el 26\% (23,5\% + 2,5\%) a las Municipalidades, además del $3 \%$ para instituciones financieras públicas, para desarrollo de las regiones Norte, Noreste y Centroeste de Brasil. El impuesto auxilia el control del comercio extranjero y la producción/consumo nacional, ejerciendo una fuerte función extrafiscal (artículos 159, I y II, y $\$ 3^{\circ}$, de la CF).

\section{e) Impuesto sobre operaciones de crédito, cambio, seguro, o relativas a titulos o valores mobiliarios - IOF (artículo 153, V, de la CF)}

- Legislación básica: artículos 63 a 67 del CTN, Ley No 5.143/1966, Decreto-Ley No 1.783/1980, artículo 58 y 59 de la Ley No 9.532/1997 y Leyes $\mathrm{No}_{s}$. 7.766/1989 y 8.894/1994, reglamentados por el Decreto No 6.306/2007 (Reglamento del "Impuesto sobre Operaciones Financieras", el RIOF) ${ }^{44}$.

\footnotetext{
${ }^{44} \mathrm{La}$ expresión "impuesto sobre operaciones financieras" merece crítica, porque el impuesto de hecho no incide sobre cualquier operación financiera, sino solo sobre las siguientes: crédito, cambio, seguro o relativa a títulos o valores mobiliarios. Por ello es que concluimos que los simples depósitos, saques u otras transacciones financieras no deben ser tributados por el impuesto.
} 
- Hechos generadores:

i) operación de crédito (préstamo de dinero, financiamiento en la compra de bienes u operación de factoring), desde que es realizada entre las siguientes personas:

- una institución financiera/asemejada y una persona física o jurídica;

- una persona jurídica cualquiera y otra persona jurídica;

- una persona jurídica cualquiera y una persona física o al revés.

ii) operación de cambio, o sea, compra/venta de moneda extranjera, operada por instituciones (bancos, corredoras, etc.), o Correos (vale postal internacional);

iii) operación de seguro (contratación de seguro de vida, de bienes o de negocios);

iv) operaciones con títulos o valores mobiliarios (títulos públicos y de capitalización, inversiones diversas, compra o venta de acciones de empresas, etc.);

v) adquisición de oro activo financiero $u$ oro instrumento cambial, siendo tributable solo la primera operación (la que destina el oro al Banco Central o institución financiera autorizada a negociarlo), conforme artículo $153, \$ 5^{\circ}$, de la CF. Obsérvese que los rendimientos o ingresos de capital en las negociaciones posteriores con el oro activo financiero están sujetos al impuesto federal sobre la renta, con las mismas alícuotas aplicables a los rendimientos de aplicaciones financieras y de ingresos de capital ${ }^{45}$.

- Sujeto activo: Uno Federal (Secretaría de la Hacienda Federal de Brasil) ${ }^{46}$.

- Sujetos pasivos:

i) el tomador del crédito o el contratante de operación de factoring es el contribuyente, pero es la institución financiera, de factoring o persona jurídica concedente quien queda responsable de la retención y recaudación del impuesto;

ii) el contratante de la operación de cambio es el contribuyente del impuesto, pero es la institución operadora del cambio quien queda responsable de la retención y recaudación del impuesto en el plazo legal;

iii) el contratante de la operación de seguro es el contribuyente del impuesto, pero es la institución seguradora quien queda responsable de la retención y recaudación;

iv) el adquirente de títulos y valores mobiliario y los titulares de aplicaciones financieras son los contribuyentes del impuesto, pero es la institución intermediadora o financiera quien queda responsable de la retención y recaudación del impuesto;

v) la institución financiera autorizada que hace la primera adquisición del oro (importado o no) dirigido a ser activo financiero o instrumento cambial.

- Bases de cálculo:

i) en la operación de crédito, es la suma involucrada en la operación o saldo deudor;

${ }^{45}$ Ley No 7.766/1989.

${ }^{46}$ Conforme artículo 3o del Decreto-Ley No 2.471/1988. 
ii) en la operación de cambio, es la suma en moneda nacional involucrada en el cambio con moneda extranjera;

iii) en la operación de seguro, es la suma de la prima pagada por el asegurado;

iv) en la operación relativa a título o valor mobiliario, es el valor de la negociación;

v) en la adquisición de oro activo financiero o instrumento cambial, es el precio de adquisición (en los límites de la cotización del mercado interno del día de la adquisición).

- Alícuotas

i) En la operación de crédito, la alícuota común es de un 0,0041\% al día. Para la micro o pequeña empresa suscrita en el régimen simplificado de tributación (SIMPLE) de la LC No 123/2006, la alícuota común se reduce a un 0,00137\% al día desde que el valor del crédito sea inferior a US\$15.000,00 ${ }^{47}$. La alícuota es del $0 \%$ en los casos de crédito para: cooperativas, empresas de exportación, producción rural, estudiantes que financien su curso superior, operaciones de financiamiento de industrias por medio de órgano oficial de fomento, etc. En cualquiera de las operaciones indicadas anteriormente, se aplica una alícuota adicional de un 0,38\% por operación ${ }^{48}$ (en ciertos casos, la alícuota incide en cada saldo mensual). La cobranza del impuesto es generalmente en la fecha de la operación o en períodos de cálculo mensuales.

ii) En las operaciones de cambio, la alícuota general es de un $0,38 \%$, pero, en la práctica son muy comunes operaciones beneficiadas con alícuota del $0 \%$, especialmente para prestigiar la entrada de recursos e inversiones extranjeros en Brasil y el cambio en las exportacciones de bienes y servicios. $Y$ en algunos pocos casos, la alícuota es de un 6\% (inversión extranjera en mercado de capitales) o un 6,38\% (adquisición de bienes y servicios del extranjero mediante uso de tarjeta de crédito). La cobranza del impuesto se hace en la liquidación de la operación de cambio.

iii) En las operaciones de seguro, la alícuota general es del 7,38\%. La alícuota es del 2,38\% para seguros de asistencia a la salud y es del $0,38 \%$ para seguros de vida, de accidentes personales, incluso seguro obligatorio DPVAT ${ }^{49}$. Diversos tipos

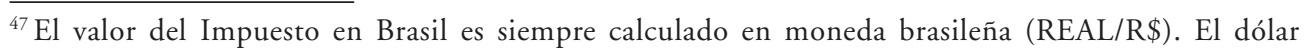
norteamericano aquí sirve solo como una referencia didáctica, y está estimado en el cambio de $\mathrm{R} \$ 2,00$ (junio/2013).

${ }^{48}$ La referida alícuota adicional fue creada para compensar la pérdida en la recaudación del Gobierno Federal generada con la extinción de la cobranza de la contribución provisional sobre transacción financiera (CPMF), a partir del 1 de enero de 2008. La CPMF era un tributo creado para financiar gastos de salud, fondos de pensiones y asistencia social, e incidía con alícuota del $0,38 \%$ sobre las transacciones financieras (Petry, Rodrigo Caramori (2011). "O passado, o presente e o futuro da tributação sobre a movimentação financeira no Brasil: IPMF, CPMF e CSS”. Revista Tributária e de Finanças Públicas, No 99, São Paulo: Revista dos Tribunais, julio-agosto, p. 226).

${ }^{49}$ DPVAT es un seguro por daños personales causados por vehículos automotrices terrestres, que todo propietario de vehículo debe contratar y pagar por obligación legal (Ley No 6.194/1974).
} 
de seguro poseen alícuota del 0\% del IOF: reseguro ${ }^{50}$, seguro de financiamiento de vivienda, seguro de crédito a la exportación, seguro aeronáutico y seguro garantía son los principales. El pago se hace juntamente con el premio del seguro.

iv) En las operaciones con títulos y valores mobiliario, las alícuotas del IOF son diversas, variando entre: un 1,5\% al día (limitado al 10\% o al 5\%) en el caso de operaciones con títulos de renta fija o variable con recursos de inversores extranjeros en ciertas condiciones, alícuota también aplicada a determinadas cesiones de acciones de empresa en bolsa de valores; el 0,5\% al día en el caso de rescate anticipado de cuotas de fondo de inversiones; el 1\% al día sobre el rendimiento anticipado en el caso de rescate o renegociación en operaciones de renta fija o fondos de inversión, además de en determinadas operaciones con derivativos cambiales. Hay varios casos de alícuota 0\%: operaciones hechas por las propias instituciones financieras, operaciones en bolsas de valores/acciones de empresas, con derechos creditorios del agronegocio o del sector inmobiliario, con algunos contratos de derivativos ${ }^{51}$, etc.

v) En las operaciones con oro activo financiero u oro instrumento cambial, la alícuota del IOF es del 1\% sobre el precio de adquisición.

El Poder Ejecutivo puede alterar las alícuotas (artículo 153, \$1º, CF), en los límites dados por la legislación del impuesto, que establece como límites lo siguiente:

- en las operaciones de crédito, alícuota mínima del $0 \%$ y máxima del 1,5\% al día ${ }^{52}$;

- en las operaciones de cambio, alícuota mínima del 0\% y máxima del 25\%; ${ }^{53}$

- en las operaciones de seguro, alícuota mínima del 0\% y máxima de 25\%; 54

- en las operaciones con títulos o valores mobiliarios, alícuota mínima del $0 \%$ y máxima del $1,5 \%$ al día; 55

- en las operaciones con oro activo financiero o instrumento cambial, alícuota mínima del $1 \%$, y alícuota máxima no prevista por la legislación. ${ }^{56}$

- Otros aspectos

i) Exenciones del impuesto:

- IOF crédito en diversas operaciones, por ejemplo, las contratadas para financiamiento de viviendas, las contratadas por misión diplomática extranjera, algunas operaciones para exportación, etc.;

\footnotetext{
${ }^{50} \mathrm{El}$ "re seguro" es una forma de "seguro entre aseguradoras", para dilución del riesgo económico entre ellas, especialmente requerido en el caso de objeto asegurado involucrado con extraordinario riesgo financiero.

${ }^{51}$ Derivativo es un instrumento financiero en el que se fijan precios para liquidación futura o cambio de posiciones en negocios, relativa a un activo/bien o negocio financiero, sirviendo para reducir, anular o gestionar los riesgos de la variación del mercado de precios del activo/bien o negocio.

${ }^{52}$ Artículo $1^{\circ}$ de la Ley No $8.894 / 1994$.

${ }^{53}$ Artículo 5o de la Ley No 8.894/1994.

${ }^{54}$ Artículo 15 de la Ley No 9.718/1998.

${ }^{55}$ Artículo $1^{\circ}$ de la Ley No 8.894/1994.

${ }^{56} \mathrm{El}$ artículo $153, \$ 5^{\circ}$, de la CF prevé la alícuota mínima del IOF oro en el $1 \%$.
} 
- IOF cambio en algunas operaciones, básicamente en la importación de bienes, en las compras de la Hidroeléctrica Itaipú Binacional, y en la contratación de cambio por misión diplomática extranjera;

- IOF seguro en algunas operaciones, básicamente el seguro de producción rural, el seguro contratado por la Hidroeléctrica Itaipú Binacional y el seguro contratado por misión diplomática extranjera;

- IOF títulos y valores mobiliarios en algunas operaciones, básicamente operaciones hechas por la Hidroeléctrica Itaipú Binacional, fondos de desarrollo regional, algunas operaciones ligadas al agronegocio y las operaciones realizadas por misiones diplomáticas extranjeras.

- Destinación de la hacienda

i) IOF en general: arcas de la Uno, para formación de reservas monetarias para aplicación por el Banco Central de Brasil en diversas funciones, como: intervención en el mercado de cambio y de títulos; apoyo a instituciones financieras, especialmente el BNDES; otros fines definidos por el Consejo Monetario Nacional (CMN); y en casos excepcionales, la recaudación puede ser destinada a socorrer instituciones financieras en intervención ${ }^{57}$. Así el impuesto auxilia el Gobierno en el control de la economía nacional (política monetaria, inflación, balance de pagos), con fuerte función extrafiscal. La previsión de la destinación está en la Ley No 5.143/1966.

ii) IOF oro: arcas de la Uno, que repasa mensualmente un $30 \%$ a los estados o DF y un $70 \%$ a las municipalidades de origen del oro (en la condición de local de la extracción o de llegada de la importación). Tal destinación está prevista en el artículo $153, \$ 5^{\circ}$, de la $\mathrm{CF}$.

\section{f) Impuesto sobre la propiedad territorial rural - ITR (artículo 153, VI, de la CF)}

- Legislación básica: artículos 29 a 31 del CTN y artículo 15 del Decreto-Ley No 57/1966, Ley No 9.393/1996, reglamentada por el Decreto No 4.382/2002 (Reglamento del ITR).

- Hecho generador: ser propietario, poseedor o titular de dominio útil de bien inmueble rural, el 1 de enero de cada año (el impuesto es anual). Inmueble rural aquí es el territorio/terreno (no los edificios y agregados) y se define de dos formas: i) por la localización, fuera de la zona urbana del municipio; o ii) por el uso del inmueble, dirigido a la producción agropecuaria o extración vegetal, aunque dentro de la zona urbana ${ }^{58}$.

\footnotetext{
${ }^{57}$ Artículo 12 de la Ley No 5.143/1966.

${ }^{58}$ Es el artículo 15 del DL No 57/1966 que define el inmueble rural por destinación. Él fue supuestamente revocado por la Ley No 5.868/1972, pero dicha ley fue juzgada inconstitucional (por vulnerar una regla con status de ley complementaria) y después suspendida por la Resolución del Senado No 313/1983.
} 
- Sujeto activo: Uno Federal (Secretaría de la Hacienda Federal de Brasil), o el municipio en el que está localizado el inmueble, en caso que el municipio haya asumido la fiscalización y cobranza mediante convenio con la Uno (artículo 153, $\$ 4^{\circ}$, III, de la CF).

- Sujeto pasivo: contribuyente del ITR es el propietario, o el titular del dominio útil o el poseedor del inmueble. En cualquiera de los casos, el contribuyente es quien goza del inmueble rural, con provecho económico. Pero pueden ser responsabilizados del pago del impuesto los adquirentes del inmueble con débito pendiente, o el agente oficial del notario de registro de inmuebles que no cuide de fiscalizar el recogimiento antes de transferir la propiedad en el caso de enajenación del inmueble sobre el que haya débito pendiente ${ }^{59}$.

- Base de cálculo: es el valor solo de la tierra (terreno) tributable, lo que se obtiene mediante una evaluación del precio de mercado de la tierra en la localidad, que lleva en consideración solo el terreno utilizable, excluyéndose de la tributación las cuotas de tierra que no puedan o no deban ser objeto de explotación económica.

- Alícuotas: están dispuestas en la "Tabla de Incidencia del ITR" constante de la Ley No 9.393/1996. Las alícuotas son progresivas extrafiscales, creciendo conforme el tamaño de la propiedad y el menor grado de utilización de la tierra (\% de utilización en relación al área total aprovechable del inmueble). Las alícuotas son las siguientes:

\begin{tabular}{|c|c|c|c|c|c|}
\hline \multirow{2}{*}{$\begin{array}{c}\text { ÁREA DEL INMUEBLE } \\
\text { RURAL } \\
\text { (en hectáreas) }\end{array}$} & \multicolumn{5}{|c|}{$\begin{array}{l}\text { GRADO DE UTILIZACIÓN DE LA TIERRA } \\
(\text { en \%) }\end{array}$} \\
\hline & $\begin{array}{l}\text { Mayor que } \\
80\end{array}$ & $\begin{array}{c}\text { Mayor que } \\
65 \text { hasta } \\
80\end{array}$ & $\begin{array}{c}\text { Mayor que } \\
50 \text { hasta } \\
65\end{array}$ & \begin{tabular}{|c|} 
Mayor que \\
30 hasta \\
50 \\
\end{tabular} & Hasta 30 \\
\hline Hasta 50 & 0,03 & 0,20 & 0,40 & 0,70 & 1,00 \\
\hline Mayor que 50 hasta 200 & 0,07 & 0,40 & 0,80 & 1,40 & 2,00 \\
\hline Mayor que 200 hasta 500 & 0,10 & 0,60 & 1,30 & 2,30 & 3,30 \\
\hline Mayor que 500 hasta 1.000 & 0,15 & 0,85 & 1,90 & 3,30 & 4,70 \\
\hline Mayor que 1.000 hasta 5.000 & 0,30 & 1,60 & 3,40 & 6,00 & 8,60 \\
\hline Superior a 5.000 & 0,45 & 3,00 & 6,40 & 12,00 & 20,00 \\
\hline
\end{tabular}

- Otros aspectos

- Cálculo del impuesto: el ITR es un impuesto cuyo cálculo es complejo y depende de mapas georeferenciados, de ahí ser común que los grandes propietarios de tierras contraten los servicios de asesoría de un ingeniero forestal especializado.

- Inmunidades contra el impuesto: conforme determina la Constitución (artículo $153, \$ 4^{\circ}$, II y $\left.150, \mathrm{VI}\right)$, las pequeñas tierras rurales (30 hectáreas en general, o hasta 50 ó 100 hectáreas en el caso de inmuebles localizados en deter-

\footnotetext{
${ }^{59}$ Acerca de esa responsabilidad por el pago del ITR, véanse, sobre todo, los artículos 130 y 134 del CTN.
} 
minadas regiones poco desarrolladas de Brasil ${ }^{60}$ desde que son explotadas por propietario que no posee otro inmueble, quedan libres del impuesto, además de las propiedades rurales de los gobiernos y de otras entidades inmunes a impuestos (instituciones de educación o de asistencia social sin fines lucrativos, etc.).

- Exenciones: la legislación del ITR exenta del impuesto los inmuebles involucrados en la reforma agraria conducida por el gobierno federal y los inmuebles rurales del mismo propietario desde que la suma de sus áreas sea igual o inferior a 30 hectáreas (ó 50 ó 100 hectáreas de tierra en el caso de zonas rurales poco desarrolladas) y el propietario no posea inmueble urbano.

- Destinación de la hacienda: arcas de la Uno Federal, que repasa el 50\% al municipio donde se localiza el inmueble rural tributado; o, directamente a las arcas del municipio integralmente (100\%), en el caso del Municipio que opte por asumir la fiscalización y la cobranza sobre los inmuebles ubicados en él (artículo 158, II, de la CF). En el caso de inmueble rural que se extienda por más de un municipio, el impuesto se dirige integralmente al municipio donde está la sede administrativa/casa del propietario o donde está localizada la mayor parte del inmueble.

\section{g) Impuesto sobre las grandes fortunas - IGF (artículo 153, VII, de la CF)}

El impuesto federal sobre las "grandes fortunas", no obstante estar previsto en la Constitución brasileña de 1988, hasta hoy no ha sido instaurado en Brasil, razón por la cual no existe ninguna legislación vigente sobre el tema. Existen anteproyectos de ley orgánica complementaria en trámite en el Congreso para instituirlo, pero la inseguridad, las dificultades técnicas y la resistencia política ante un impuesto de esa naturaleza impiden su aprobación. La destinación de lo recaudado sería el Fondo de Combate a la Pobreza (artículo 80, III, del ADCT) ${ }^{61}$.

\section{b) Impuestos residuales - IRD \\ (artículo 154, I, de la CF)}

La Constitución brasileña también le atribuye competencia a la unión federal para, por medio de ley complementaria, instituir impuestos residuales, o sea, cuyo hecho generador o base de cálculo sean inéditos en relación a los ya previstos para los impuestos del gobierno federal, de los estados, del DF o municipalidades. En caso que el hecho generador a ser escogido por la Unión, en el ejercicio de esa competencia residual, tenga como núcleo una riqueza circulante (involucrada

\footnotetext{
${ }^{60}$ Básicamente dichas regiones seleccionadas se localizan en Amazonia, en noreste-seco, y en Pantanal.

${ }^{61}$ Acto de las Disposiciones Constitucionales Transitorias, constante en la parte final de la Constitución de 1988.
} 
en una cadena de circulación económica), el nuevo impuesto deberá ser no acumulativo, o sea, deberá permitir que la incidencia en una etapa de la circulación sea compensada/reducida por el impuesto pagado en la etapa anterior. Desde la promulgación de la Constitución (1988), todavía no han sido instituidos los impuestos residuales en Brasil ${ }^{62}$. Si se crea el impuesto residual, el 20\% del valor recaudado por la Unión deberá ser repasado a los estados y al DF (artículo 157, II, de la Constitución Federal).

\section{i) Impuestos extraordinarios de guerra - IEG (artículo 154, II, de la CF)}

La Constitución de Brasil autoriza a la unión federal a instituir, ante la inminencia de una guerra externa o durante su desarrollo, impuestos extraordinarios, para financiar los gastos generados del conflicto ${ }^{63}$. Dichos impuestos podrán ser creados teniendo como la hipótesis de incidencia cualquier manifestación de riqueza tributable, incluso las ya usadas como hecho generador de impuestos típicos de los estados/DF o de las municipalidades. El legislador tiene en este punto una amplia libertad, pero deberán ser obedecidos los derechos fundamentales de los ciudadanos contribuyentes, prohibidos los impuestos de guerra que no presten obediencia a la capacidad contributiva o que sean confiscatorios. Con el fin de la guerra, el impuesto deberá extinguirse gradualmente, en el plazo máximo de hasta 5 años, de acuerdo a la regla complementaria incluida en el artículo 76 del CTN. Si se crea ese impuesto, el 100\% del monto recaudado permanecerá con la Unión Federal.

\footnotetext{
${ }^{62}$ Es importante recordar que el extinto "impuesto sobre transacciones financieras" (1994) nunca ha sido un impuesto residual, ya que su fundamento de institución era la Enmienda Constitucional No 3/1993 y no el artículo 154, I, de la Constitución Federal. Sobre el tema, ver nuestro estudio: PETrY (2011), pp. 225-234.

${ }^{63}$ Es importante destacar que la Constitución de Brasil entiende como una absoluta excepcionalidad la participación del país en una guerra externa, y lo hace colocando como principios de las relaciones internacionales de Brasil, en su artículo 4o: independencia nacional, prevalencia de los derechos humanos, autodeterminación de los pueblos, no intervención, igualdad, defensa de la paz, solución pacífica de los conflictos, repudio al terrorismo y al racismo, cooperación entre los pueblos y concesión de asilo político. Entonces entendemos que, si la guerra externa no está justificada en dichos principios, el eventual cobro de impuesto extraordinario de guerra podrá ser contestada por los contribuyentes, por ausencia de presupuesto fáctico al tributo extraordinario. También sería ilegítimo el cobro en el caso de guerra civil. Actualmente Brasil no está involucrado en ninguna guerra externa (existe sólo ayuda militar prestada por militares en misión de paz/control en Haití y en algunos pocos países, en intervenciones por la ONU), pero el país ya se ha involucrado en siete guerras externas, que fueron: la Guerra de Independencia de Brasil (1822-1825) contra el Reino de Portugal; la Guerra de la Región Cisplatina (1825-1828) y la Guerra de la Región del Plata (1851-1852), ambas contra Argentina; la Guerra contra Uruguay (1864); la Guerra contra Paraguay (1864-1870); la Primera Guerra Mundial (1914-1918) contra Alemania y aliados; y la Segunda Guerra Mundial (1939-1945) contra Alemania y sus aliados Italia y Japón.
} 


\subsubsection{Impuestos de los estados y del distrito federal (DF)}

a) Impuesto sobre transmisión causa mortis y donación, de cualquier bien o derecho - ITCMD

(artículo 155, I, de la CF)

- Legislación básica: artículos 35 del CTN ${ }^{64}$, Resolución del Senado Federal No 9/1992, y leyes estatales y sus reglamentos. En el Estado de São Paulo, por ejemplo, rige la Ley Estatal No 10.705/2000, reglamentada por el Decreto Estatal No 46.655/2002.

- Hechos generadores: i) transmisión de cualesquiera bienes o derechos por sucesión en virtud de la muerte del titular de los referidos bienes; o ii) delación de bienes o derechos.

- Sujeto activo: estados y DF (Secretaría de Estado de la Hacienda).

- Sujeto pasivo: persona física o jurídica. i) En la sucesión causa mortis, los contribuyentes son como regla los herederos o legatarios. ii) En la donación, el contribuyente en regla es quien recibe los bienes (donatario), todo depende de lo que disponga la ley de cada estado. Generalmente, donadores y personas que intervengan en las transmisiones y registros (oficiales de notarías de registro de inmuebles, etc.) pueden ser responsabilizados por el pago del ITCMD en caso de que el contribuyente no lo tenga.

- Base de cálculo: es el valor de los bienes transmitidos en sucesión causa mortis o por donación. El valor debe someterse a la evaluación oficial, y en el caso de la sucesión por muerte, la evaluación se realiza durante el proceso judicial de inventario y división de los bienes entre los herederos y legatarios. En el caso de inventario y división extrajudiciales, el impuesto también deberá ser recaudado, bajo la fiscalización de la autoridad estatal ${ }^{65}$.

- Alícuotas: las alícuotas varían de acuerdo al estado, pero deben respetar el límite máximo de un 8\% (Resolución del Senado No 9/1992). Está permitido que los estados fijen una única alícuota o diversas alícuotas, incluso escalonadas progresivamente, creciendo conforme el valor de la base de cálculo ${ }^{66}$. En el Estado de São Paulo, por ejemplo, la alícuota es del $4 \%{ }^{67}$. Pequeños valores son exentos.

\footnotetext{
${ }^{64} \mathrm{El}$ artículo 35 del CTN trae pocas normas generales sobre el impuesto, y solo en lo que se refiere a la transmisión de bienes inmuebles por sucesión en virtud de la muerte (causa mortis), por herencia o testamento. Las demás hipótesis de incidencia del impuesto (es decir, la transmisión causa mortis de bienes muebles o la donación de bienes) no poseen normas generales en el CTN.

${ }^{65}$ La Ley Federal No 11.441/2007 es la base legal para el inventario y partición de bienes extra judicialmente.

${ }^{66} \mathrm{La}$ progresividad fiscal de las alícuotas del ITCMD está autorizada por el artículo 2o de la Resolución del Senado Federal No 9/1992, pero es polémica. El Supremo Tribunal Federal brasileño pasó a admitir la progresividad de las alícuotas del impuesto ITCMD recientemente, en el juicio del RE No 562.045/RS.

${ }^{67}$ Alícuota en la Ley Estatal No 10.705/2000. En el Estado de Santa Catarina las alícuotas son progresivas: el 1\%, 3\%, 5\%, 7\% y el 8\% (Ley Estatal No 13.136/2004). En el Estado del Paraná la alícuota es única: el 4\%.
} 
- Otros aspectos

- La incidencia y cobranza en el caso de donaciones o herencias originadas en el extranjero todavía necesita ser regulada por ley complementaria (hasta hoy no dictada).

- En la separación o divorcio de parejas, en caso que la división de los bienes sea desigual entre ellos, la parte excedente se considera donación, en regla sujeta al impuesto.

- Destinación del ingreso: el valor total recaudado se destina a las arcas de los estados y DF.

\section{b) Impuesto sobre circulación de mercancías y servicios de transporte interestatal, intermunicipal y de comunicación - ICMS (artículo 155, II, de la CF)}

- Legislación básica: Ley Complementaria No 87/199668, Resoluciones del Senado Federal No 22/1989, 95/1996 y 13/2012, y leyes estatales. En el Estado de São Paulo, por ejemplo, rige la Ley Estatal No 6.374/1989, reglamentada por el Decreto Estatal No 45.490/2000 y sus modificaciones (Reglamento del ICMS/SP).

- Hechos generadores:

i) operaciones relativas a la circulación de mercancías (ventas y asemejadas, incluso el suministro de alimentación en restaurantes, bares, etc.);

ii) operaciones de importación de mercancías o de servicios de transporte o comunicación;

iii) prestación de servicios de transporte de bienes o pasajeros entre un estado y otro o entre un municipio y otro;

iv) servicios de comunicación (telefonía fija y móvil, televisión por cable y acceso a Internet $)^{69}$;

v) remate en subasta de mercancías confiscadas o abandonadas en la aduana.

- Sujeto activo: estados (Secretaría de Estado de la Hacienda) y el DF.

- Sujeto pasivo: persona física o jurídica.

i) En la circulación de mercancías, los contribuyentes son las industrias y los comerciantes que las venden.

\footnotetext{
${ }^{68}$ El CTN originalmente preveía normas generales sobre el impuesto, pero dichas normas fueron substituidas por normas constantes en otras leyes complementarias. La principal en vigor es la LC No 87/1996.

${ }^{69}$ La Enmienda Constitucional No 42/2003 introdujo en el artículo 155, $\$ 2^{\circ}$, X, “d”, de la Constitución brasileña una hipótesis de inmunidad tributaria contra el cobro de ICMS en los servicios de comunicación por radiodifusión de sonidos (radio) o de sonidos e imágenes (televisión) de recepción gratis. Antes de esa Enmienda, los estados cobraban el impuesto ICMS de las Tvs y radios, sobre el valor de los anuncios de marketing/publicidad vehiculados y pagos por empresas y otros anunciantes. En relación al ICMS sobre acceso a Internet, el tema es polémico y criticado por los contribuyentes. El Superior Tribunal de Justicia brasileño juzgó que no incide ICMS en el caso de servicio de Internet pulsada, pero tal vez aún pueda revisar su juicio en el caso del proveedor de Internet banda ancha.
} 
ii) En la importación de mercancías o servicios del extranjero, contribuyente es el destinatario brasileño de la importación (incluso la persona física no comerciante).

iii) En los servicios de transporte, el contribuyente es el prestador del servicio.

iv) En el servicio de comunicación, el contribuyente es el prestador del servicio.

v) En el remate en subasta de mercancía, el contribuyente es el adjudicador.

Establecimientos de la misma empresa son tratados como contribuyentes diferentes. Los transportadores o almacenadores de mercancías pueden ser responsabilizados por el pago del ICMS-mercancías, en caso de falta de documentos fiscales u otras irregularidades.

- Base de cálculo: varían entre las operaciones, y los estados también pueden aplicar reducciones en el valor de la base de cálculo, como forma de incentivo a ciertos sectores.

i) ICMS mercancías: valor de la operación, incluyendo valor del flete/transporte para entrega de la mercancía (y no sólo el valor de la mercancía);

ii) ICMS importación: suele ser el valor aduanero (CIF) + impuesto de importación + IPI importación + valor del IOF (cambio) + adicional al flete u otros tributos o gastos aduaneros de la operación, y la base también es "por dentro de la operación" (o sea, la alícuota del ICMS corresponde a un porcentaje del valor de la operación, y no un porcentaje del valor de las mercancías solamente);

iii) ICMS transporte: es el valor de la operación de transporte;

iv) ICMS comunicación: es el valor de la operación de comunicación.

v) ICMS- remate: es el valor del remate en subasta.

- Alícuotas: varían de acuerdo al tipo de operación, al tipo de mercancía o servicio, y también varían entre los 26 estados y el DF, pero deben respetar el límite mínimo del 7\% (posible de reducción por medio de convenio entre los estados). No existe un límite de alícuota máxima ${ }^{70}$. El tema es complejo, veámoslo mejor.

i) ICMS mercancías: en general, las alícuotas estándar de ICMS en todos los estados para operaciones internas (dentro del mismo estado) están entre un 7\%, $12 \%, 17 \%, 18 \%$ y un $25 \%$, dependiendo del tipo de mercancía ${ }^{71}$. Sólo algunas

\footnotetext{
${ }^{70}$ En la práctica, tenemos noticia de que la mayor alícuota de ICMS en vigor en Brasil es un 38\% (cobrada por el Estado de Bahía en la venta de armas y municiones para el ciudadano común).

${ }^{71}$ En el Estado de São Paulo, por ejemplo, las alícuotas varían entre el 7\% (huevos), el 12\% (alimentos, automóviles), el 18\% (ropas, mercancías en general) y el 25\% (energía eléctrica, gasolina y alcohol combustible, armas, pieles, perfumes, cigarrillos, bebidas alcohólicas). En el Estado del Paraná, las alícuotas del ICMS mercancías varían entre el 7\% (alimentos), el 12\% (ropas y automóviles), el 18\% (mercancías en general), el 25\% (armas, pieles, perfumes), el 28\% (gasolina y alcohol combustible) y el 29\% (energía eléctrica, cigarrillos, bebidas alcohólicas). En Amazonas las alícuotas son un 12\%, 17\% o un 25\%. Como vemos se adopta sólo parcialmente la técnica de la selectividad en función de la esencialidad de la mercancía (lo que es esencial debe ser menos tributado). El problema es que muchos estados brasileños permiten reducciones en la base de cálculo del ICMS, de forma que la alícuota efectiva acaba siendo diferente de la alícuota nominal. El Estado del Rio de Janeiro, por ejemplo, tiene muchos casos de reducción de la base de cálculo del ICMS. Son alícuotas efectivas en RJ: el 4\% (aeronaves), el 7\% (alimentos), el 12\%
} 
mercancías reciben otras alícuotas, y, generalmente, son mayores $(28 \%, 30 \%$, $35 \%$, etc.). En el caso de ventas interestatales de mercancías para consumo final en empresas comerciales o industriales, el ICMS se dividide entre el estado del vendedor y el estado del comprador de las mercancías, siendo aplicadas alícuotas especiales en la operación (en el origen será cobrado un $7 \%$ o un $12 \%$, y en el destino la alícuota varía de acuerdo al estado). En el caso de ventas interestatales, de mercancía importada, la alícuota es única en cualquier estado brasileño: un 4\%.

ii) ICMS importación: las alícuotas son las mismas aplicadas al ICMS ventas, variando de acuerdo a la mercancía $(7 \%, 12 \%, 18 \%$ o el $25 \%$, en el Estado de São Paulo $)^{72}$. Por lo tanto, el ICMS importación en los estados brasileños varía en general entre un $7 \%$ hasta un $25 \%$ en la importación. La alícuota del ICMS en el remate de bienes en la aduana suele ser idéntica a la alícuota aplicable a la importación.

iii) ICMS transporte: las alícuotas aplicables a las operaciones dentro del mismo estado varían generalmente entre un 12\% (São Paulo, Paraná) o un 17\% (varios estados $)^{73}$. En las operaciones de transporte de un estado a otro, cuando el destinatario es una empresa comercial o industrial (contribuyente del impuesto), el ICMS se divide entre el estado de salida y el estado de llegada, siendo aplicadas alícuotas específicas: el estado de salida cobra un $7 \%$ o un $12 \%$ en el caso de transporte terrestre o acuático, y un $4 \%$ en el caso de transporte aéreo; ya el estado de llegada del transporte cobra el ICMS con otra alícuota, que varía de acuerdo al estado ${ }^{74}$.

iv) ICMS comunicación: las alícuotas generalmente son altas, y varían entre un 17\% (Acre), 25\% (São Paulo), 27\%, 28\%, 29\% (Paraná), 30\% a 35\% (Rondonia).

- Otros aspectos

- Cálculo del impuesto: el ICMS es un impuesto no acumulativo. El valor del impuesto debido en un período de cálculo (como regla, mensual) es el resultado de dos operaciones matemáticas: primero se hace la incidencia de las alícuotas sobre los valores de las operaciones del período; del resultado, se hace la sustracción/ compensación del valor del impuesto debido/pago en las operaciones anteriores. En el caso del ICMS importación, el régimen de cálculo es diferente: el impuesto

(automóviles), el 24\% (alcohol combustible), el 26\% (cigarrillos, bebidas alcohólicas), por ejemplo. Ya las alícuotas nominales en RJ son un 6\%, 7\%, 12\%, 18\%, 20\%, 25\%, 30\%, 35\% y un 37\%. Es raro que un estado brasileño fije alícuota de ICMS en número no entero, pero es el caso del óleo diésel para transporte urbano en Pernambuco (8,5\%). Algunos estados cobran el ICMS con una alícuota adicional del $2 \%$ en el caso de mercancías superfluas o de lujo, con base en la autorización del artículo 82, $\$ 1^{\circ}$, del ADCT de la Constitución Federal brasileña, para financiar el Fondo de Combate a la Pobreza.

${ }^{72}$ Así también es en Río de Janeiro, en Amapá, entre otros Estados.

${ }^{73}$ Mato Grosso, Mato Grosso do Sul, Maranhão, Alagoas, Acre, Amapá, Amazonas, Bahia, Ceará, etc.

${ }^{74} \mathrm{La}$ cobranza del impuesto ICMS en el transporte terrestre, acuático y aéreo es objetivo de polémica, y el Supremo Tribunal Federal ya exentó a las empresas de aviación del pago del tributo (ADIs 1.600 y 2.669). 
es debido por operación, y por lo tanto, no depende de la recaudación mensual del ICMS ventas del período ${ }^{75}$.

- Beneficios fiscales: el ICMS es un impuesto muy complejo y altamente problemático en Brasil, pues involucra el interés de 26 estados y del DF, lo que exige que exenciones, reducciones y beneficios fiscales sean decididos de común acuerdo entre ellos, por medio de convenios, para reducir la llamada "guerra fiscal" (disputa para atraer inversiones de empresas, mediante beneficios fiscales).

- Sustitución tributaria: la legislación del ICMS prevé casos polémicos de tributación anticipada, llamada de "sustitución tributaria para delante de la cadena de circulación de las mercancías", por la cual las industrias generalmente son responsabilizadas del pago del total del impuesto que sería debido en las diversas etapas de circulación/ventas. El cálculo del ICMS sustitución tributaria se hace con base en precio estimado de la venta al consumidor final, reduciéndose así el riesgo de evasión fiscal, ya que no será necesario fiscalizar todas las etapas de circulación de las mercancías, pues el impuesto se paga al inicio de la cadena.

- Destinación de los ingresos: arcas de los estados, que deben repasar a sus municipalidades el $25 \%{ }^{76}$. De ese $25 \%$, la mayor parte (el $75 \%$ o más) se divide entre las municipalidades desigualmente, recibiendo más ingresos las municipalidades en cuyos territorios estén ubicados los establecimientos/empresas con las mayores operaciones y valores de ventas, servicios e importaciones (artículo 158, IV y $\$$ único, de la CF).

\section{c) Impuesto sobre la propiedad de vehiculos automotrices - IPVA (artículo 155, III, CF)}

- Legislación básica: no existen reglas generales sobre el impuesto IPVA en el CTN, valiendo solo las leyes de cada estado. Todos los estados de Brasil cobran el impuesto. En el Estado de São Paulo, por ejemplo, el impuesto está previsto en la Ley Estatal No 13.296/2008.

- Hecho generador: ser propietario de vehículo automotriz al 1 de enero de cada año.

- Sujeto activo: estado o DF (Secretarías de Hacienda) donde se registra el vehículo.

- Sujetos pasivos: propietarios de vehículos automotrices.

- Base de cálculo: valor del vehículo automotriz (la evaluación estatal admite contraprueba, ya que está fundamentada en una tabla genérica adoptada por el gobierno estadual).

\footnotetext{
${ }^{75}$ La legitimidad de la exigencia del ICMS importación en cada operación, independiente del cómputo mensual, está consagrada por el Superior Tribunal de Justicia brasileño (STJ, 2a Turma, Resp No 16.951/ SP, Rel. Ministro Adhemar Maciel, j. unánime el 05/12/1996, DJU el 03/02/1997, entre muchos otros).

${ }^{76} \mathrm{El}$ DF no está dividido en municipalidades, por ello no le transfiere a nadie su ingreso con el ICMS.
} 
- Alícuotas: varían entre los estados, y todavía se admiten alícuotas diferenciadas de acuerdo con el tipo y utilización del vehículo. No hay todavía alícuota mínima o máxima. Las alícuotas del IPVA en los estados brasileños varían generalmente entre el $1 \%, 1,5 \%, 2 \%, 2,5 \%, 3 \%, 3,5 \%$ y el 4\%. Algunos estados reducen a la mitad la alícuota del vehículo en determinadas condiciones (por ejemplo, el usado para arrendamiento) y vehículos antiguos están exentos del impuesto.

- Destinación del ingreso: arcas de los estados y del DF, que deben repasar el $50 \%$ a sus municipalidades donde estén registrados los vehículos automotrices. ${ }^{77}$

\subsubsection{Impuestos de las municipalidades}

\section{a) Impuesto sobre la propiedad predial y territorial urbana - IPTU (artículo 156, I, CF)}

- Legislación básica: artículos 32 a 34 del CTN, Ley Federal No 10.257/2001 (Estatuto de las Ciudades), leyes municipales y sus reglamentos.

- Hecho generador: ser propietario de inmueble urbano, territorial y predial (incluyéndose aquí los terrenos, casas, apartamentos en edificios, edificios comerciales o industriales), al día 1 de enero de cada año (incidencia y cálculo anual).

- Sujeto activo: municipio o DF (Secretarías de Hacienda o Finanzas), donde está ubicado el inmueble urbano.

- Sujetos pasivos: propietarios, titulares del dominio útil o poseedores con ánimo de dominio sobre el inmueble.

- Base de cálculo: valor del inmueble (la evaluación estatal admite contraprueba, ya que se basa en una tabla genérica de valores inmobiliarios, elaborada y actualizada por el ayuntamiento de cada municipio).

- Alícuotas: las alícuotas varían entre las 5.570 municipalidades, y pueden ser progresivas según criterios de urbanización (IPTU urbanístico, progresivo en el tiempo), valor del inmueble o la ubicación o uso del inmueble (residencial, comercial, etc.). La alícuota mínima es del $0 \%$ y no hay alícuota máxima expresa, a no ser para el caso de IPTU urbanístico (el progresivo en el tiempo, que aumenta cada año, para forzar al propietario a alguna conducta de aprovechamiento de la propiedad) $^{78}$, cuya alícuota puede alcanzar hasta un 15\% (Ley No 10.257/2001).

\footnotetext{
${ }^{77}$ El DF no está dividido en municipalidades, por tanto, se queda con el 100\% de la recaudación del impuesto.

${ }^{78}$ Prevé la Ley No 10.257/2001: Artículo 5o "Ley municipal especifica para área incluida en el plan director podrá determinar las cuotas, la edificación o la utilización compulsorias del suelo urbano no edificado, subutilizado o no utilizado, debiendo fijar las condiciones y los plazos para implementación de la referida obligación". En el caso que el propietario no cumpla las determinaciones, podrá ser cobrado IPTU progresivo en el tiempo: Artículo 7-"En caso de no cumplimiento de las condiciones y de los plazos previstos en la forma del caput del artículo 5o de esta Ley, o no siendo cumplidas las etapas previstas en el $\$ 5^{\circ}$ del artículo 5o de esta Ley, el municipio procederá a la aplicación del impuesto sobre la propiedad predial y territorial urbana (IPTU) progresivo en el tiempo, mediante la majoración de la alícuota por el plazo de cinco años seguidos. S $1^{\circ}$ El valor de la alícuota a ser aplicado cada año será fijado en la ley especifica a que se refiere el caput del artículo 5o de esta Ley y no excederá
} 
En las grandes capitales brasileñas, las alícuotas del IPTU común varían generalmente entre un $0,20 \%$ y un $3 \%{ }^{79}$.

\section{b) Impuesto sobre la transmisión de bienes inmuebles - ITBI (artículo 156, II, de la CF)}

La legislación básica del ITBI está en las leyes municipales y sus reglamentos, no habiendo normas generales nacionales en el CTN. Si es cobrado por las municipalidades en virtud de la transmisión onerosa de bienes inmuebles (urbanos o rurales) y derechos entre personas vivas (la transmisión por muerte/herencia o donación es tributada por los estados). El cobro es muy común en la compra/ venta de casas, apartamentos, edificios y terrenos. Las alícuotas varían entre las 5.570 municipalidades y diversas municipalidades cobran alícuotas progresivas conforme el valor del inmueble. En las grandes capitales brasileñas, las alícuotas varían generalmente entre el $0,5 \%$ y el $3 \%$, siendo la alícuota más común en las capitales, en promedio, del $2 \%$. El ingreso se destina a las arcas del municipio donde está ubicado el inmueble.

\section{c) Impuesto sobre servicios - ISS (artículo 156, III, de la CF)}

La legislación básica del ISS (o ISSQN) ${ }^{80}$ está en la LC No 116/2003, en una parte del Decreto-Ley No 406/1968, y en las leyes municipales y sus reglamentos. Es cobrado por las municipalidades sobre las empresas, sociedades profesionales y personas físicas que prestan servicios (excluidos los servicios de transporte intermunicipal y de comunicación, tributados por los estados/DF). La alícuota

a dos veces el valor referente al año anterior, respetada la alícuota máxima del quince por ciento. $\$ 2^{\circ}$ Caso la obligación de cotizar, edificar o utilizar no esté atendida en cinco años, el municipio mantendrá la cobranza por la alícuota máxima, hasta que se cumpla la referida obligación, garantizada la prerrogativa prevista en el artículo $8^{o}$. $\$ 3^{\circ}$ Está prohibida la concesión de exenciones o de amnistía relativas a la tributación progresiva de que trata este artículo".

${ }^{79}$ Todavía, actualmente una significativa cuota de municipalidades brasileñas (más de 100 municipalidades, o sea, sobre un $2 \%$ del total) simplemente no cobra el impuesto o lo hace mediante previsión de alícuota $0 \%$ para todos los inmuebles urbanos en su territorio. Para mayores informaciones sobre recaudación del IPTU en Brasil, véase el interesante estudio del Instituto de Pesquisa (Investigación) Económica Aplicada (IPEA): "Política fiscal y justicia social en Brasil: el caso del IPTU". Disponible en: <http://caderno.allanpatrick. net/wp-content/uploads/2009/08/ipea-comunicado-presidencia-28-iptu-27-08-2009.pdf> [Consulta: 13 junio 2013]. Otra encuesta publicada por el IPEA mostró que en 2003 solo 1/3 de las viviendas en Brasil pagaba IPTU. Eso se da de modo común por diversos motivos, como la no incidencia, falta de cobranza por falta de estructura fiscal de las administraciones públicas municipales, beneficios fiscales legales, falta de registro de una cuota de los inmuebles del municipio en la administración tributaria, desactualización del valor de las plantas genéricas de valores (base de cálculo del IPTU) etc. El estudio citado está disponible en: <http://www.ipea.gov.br/portal/images/stories/PDFs/comunicado/110920_comunicadoipea112.pdf> [Consulta: 13 junio 2013].

${ }^{80}$ ISSQN: impuesto sobre servicios de cualquier naturaleza, otra denominación para el ISS. 
mínima es un $2 \%$ y la máxima un $5 \%$ sobre el precio del servicio ${ }^{81}$. Las alícuotas en las municipalidades brasileñas varían, por lo tanto, entre un 2\% y un 5\%. Los profesionales autónomos que actúan individualmente y las sociedades uniprofesionales prestadoras de servicios personalizados (sociedades de abogados, médicos, ingenieros, etc.) pueden pagar el ISS calculado mediante alícuota sobre una base en valor fijo, o directamente en valores fijos, en períodos generalmente trimestrales o anuales, en régimen simplificado ${ }^{82}$. El ingreso recaudado queda con el propio municipio que recaudó el impuesto.

\subsection{Tasas (artículo 145, II, de la CF)}

La Constitución de Brasil autoriza al gobierno federal, a los estados, al distrito federal y a los municipios la institución y cobranza de tasas, que son tributos cuyos hechos generadores consisten en una actuación de la Administración específica, dirigida al contribuyente. La actuación estatal que fundamenta la cobranza de una tasa puede ser:

i) la prestación de un servicio público (en el interés del contribuyente o de la colectividad), efectivo o potencial, específico (determinado) y divisible (a punto de ser posible identificar cuál es el costo aproximado de la prestación para cada contribuyente); o

ii) el ejercicio del poder de policía del gobierno (actos de fiscalización, control o restricciones a determinadas actividades civiles o económicas, para atender el interés público).

Debido a la amplitud de las actividades federales, existe una gran cantidad de tasas cobradas por el gobierno federal, y en menor número quedan las tasas en cada estado y en cada municipio, fijadas conforme el interés de la legislación local. El volumen de tasas y sus valores en Brasil son muy variados debido a la dinámica de la actividad estatal en las tres esferas de gobierno.

\subsection{Contribución de mejoría (artículo 145, III, de la CF)}

La Constitución también autoriza que el gobierno federal, los estados/DF y las municipalidades instituyan y cobren un tributo llamado "contribución de mejoría", cuyo hecho generador es la valorización de un bien inmueble generada por obra

\footnotetext{
${ }^{81}$ La alícuota mínima está prevista en el artículo 88 del ADCT de la CF/1988 (redacción dada por la Enmienda No 37/2002) y la alícuota máxima está prevista en el artículo 8º de la Ley Complementaria No 116/2003.

${ }^{82}$ El valor del llamado "ISS fijo" en regla es menos oneroso que el que resultaría de la aplicación de un porcentaje (\%) sobre la facturación total de la actividad. En algunas de las más grandes capitales de Brasil las cobranzas de ISS fijo rondan los U\$ 200,00/año y U\$ 500,00/año para cada profesional ( $v$. gr. municipalidades de São Paulo, Río de Janeiro y Curitiba) y algunas profesiones más simples están exentas del impuesto. El menor gravamen del ISS fijo está justificado por la diferencia económica (capacidad contributiva) entre las actividades de prestación de servicio individual y las actividades de prestación de servicio mediante empresas (carácter empresarial/comercial).
} 
pública (construcción de plazas, vías especiales de tráfico, etc.). Ese tributo no es muy cobrado por los gobiernos en Brasil.

\subsection{Préstamo obligatorio (artículo 148 de la CF)}

Para atender a gastos extraordinarios, resultantes de calamidad pública (inundaciones, sequías, etc.), de guerra externa o su inminencia, o en el caso de inversión pública de carácter urgente y relevante interés nacional, la Constitución brasileña autoriza al gobierno federal que, por medio de ley complementaria (quórum más exigente), instituya y cobre un tributo denominado "préstamo obligatorio". El préstamo obligatorio es un tributo que se asemeja a los impuestos, incidiendo sobre cualesquiera manifestaciones de riqueza, pero su cobranza es temporal y el valor recaudado debe ser devuelto tras determinado período de tiempo. Dicho tributo, que era común hasta el inicio de la década de 1990, no es cobrado más actualmente en Brasil.

\subsection{Contribuciones especiales (artículos 149 y otros, de la CF)}

Las contribuciones especiales son tributos muy comunes en Brasil, ocupando un significativo espacio en la carga tributaria brasileña, al lado de los impuestos ${ }^{83}$. La mayoría de las contribuciones incide sobre manifestaciones de riqueza, como ocurre con los impuestos. Son tributos cobrados casi exclusivamente por el gobierno federal y cuya recaudación atiende a gastos indicados por la propia Constitución, diferente de los impuestos, cuya destinación, en regla, está prevista sólo en la ley presupuestaria anual.

\subsubsection{Contribuciones sociales generales (artículos 149, 212, 550, y 240, de la CF)}

Son contribuciones creadas por leyes del gobierno federal, cuya cobranza se destina a recaudar fondos para la actuación de entidades que representan el interés público en el ámbito del orden social, especialmente en la educación y en la promoción de los demás derechos sociales indicados por la Constitución. Las principales de esas contribuciones son:

a) contribución del sueldo-educación, cobrada a las empresas e incidente en la planilla de sueldos, con alícuota de un 2,5\%;

b) contribuciones a los servicios de aprendizaje y promoción social, administrados por las respectivas entidades empresariales y sindicales (industria, comercio,

\footnotetext{
${ }^{83}$ Petry, Rodrigo Caramori (2004a). "As contribuiçôes especiais ao longo das Constituiçôes brasileiras: um tributo sui generis". Revista de Estudos Tributários, No 40, noviembre-deciembre, Porto Alegre: Síntese e IET, p. 157.
} 
servicios, etc.), cobradas a las empresas e incidentes en la planilla de sueldos, con alícuota de 2,5\%.

\subsubsection{Contribuciones para la seguridad social (artículos 149, 195, 239 y otros, de la CF)}

Son contribuciones cobradas con base en diversas leyes federales, cuya recaudación financia los servicios públicos de salud, seguridad y asistencia social.

\subsubsection{Contribuciones para la seguridad social en general (artículo 195 de la CF)}

Dichos tributos financian cualesquiera de las actividades ligadas a la seguridad social y están previstos en diversas leyes federales. Corresponden a las siguientes contribuciones:

a) Contribución para el financiamiento de la seguridad (COFINS), cobrada a las empresas en general, e incide sobre el rendimiento total de la actividad económica o sólo sobre la facturación obtenida con ventas y servicios, con alícuotas del 7,6\% sobre el rendimiento (aplicándose un cálculo que impide la incidencia cumulativa a lo largo de la cadena de circulación económica) o del 3\% ó 4\% ${ }^{84}$ sobre la facturación (cobranza cumulativa).

b) Contribución para el programa de integración social (PIS) ${ }^{85}$, cobrada a las empresas en general, e incide sobre el rendimiento total de la actividad económica o sólo sobre la facturación obtenida con ventas y servicios, de la misma forma que la COFINS pero con alícuotas del 1,65\% (para cálculo no cumulativo) o del $0,65 \%$ (cumulativo).

c) Contribución para el programa de integración social (PIS), cobrada de las entidades sin fines lucrativos, e incide sobre la hoja de sueldos, con alícuota del 1\%.

d) Contribuciones para el financiamiento de la seguridad social y para el programa de integración social, incidentes en las importaciones (COFINS importación y PIS importación), cobradas de las personas físicas y de las empresas en general, e inciden sobre el valor de las importaciones de bienes, mercancías o servicios, con alícuotas del 7,6\% (COFINS importación) y el 1,65\% (PIS importación).

e) Contribución al programa de formación de patrimonio del servidor público (PASEP), cobrada de las entidades públicas (gobierno federal, estados, DF y municipalidades), e incide sobre los ingresos públicos recaudados y transferencias de dinero público, con alícuota del $1 \%$.

\footnotetext{
${ }^{84} \mathrm{La}$ alícuota del $3 \%$ es general y la alícuota del $4 \%$ es específica para instituciones financieras/bancos.

${ }^{85}$ El PIS, administrado por el Gobierno Federal, se destina actualmente a financiar el beneficio del segurodesempleo y un bono anual en dinero efectivo para auxiliar a los trabajadores de menor renta salarial (PETRY, Rodrigo Caramori (2009b). Contribuiçôes ao PIS/Pasep e Cofins. São Paulo: Dialética).
} 
f) Contribución social sobre el lucro netos (CSLL), cobrada a las empresas en general, e incide sobre el lucro netos, con alícuotas del $9 \%$ o del $15 \%{ }^{86}$.

g) Contribuciones sobre el rendimiento obtenido con concursos de pronósticos (apuestas y sorteos), cobrada de las entidades públicas o privadas autorizadas a explotar tal actividad, con alícuotas diversas (5\%, 7,95\%, 18\%, etc., incidentes sobre el rendimiento de las apuestas) y cuya recaudación está destinada a varios fines además de la seguridad social.

h) Contribuciones residuales (artículo $195, \$ 4^{\circ}$, de la CF), a ser creadas por el gobierno federal, por medio de ley complementaria, no existiendo actualmente ninguna cobranza en vigor.

\subsubsection{Contribuciones para la seguridad social de los trabajadores en general}

Estas contribuciones, cobradas por el gobierno federal con base en la Ley No 8.212/1991 y otras leyes, están destinadas exclusivamente al financiamiento de los beneficios de la seguridad (jubilaciones, pensiones, auxilios por accidentes, etc.), y son debidas por las empresas y empleadores, y por los trabajadores/asegurados:

a) Contribución a la seguridad sobre la hoja mensual de sueldos de los empleados, cobrada a las empresas y demás empleadores, con alícuota del $20 \%$ en general $^{87}$; y en algunos sectores de la economía (clubes deportivos de fútbol y producción rural/agroindustrial) la alícuota del $20 \%$ sobre la hoja de sueldos se sustituye por una alícuota del $5 \%$ sobre el rendimiento obtenido con la venta de ingresos, o del $2 \%$ o un $2,5 \%$ sobre el rendimiento obtenido con la venta de la producción rural/agroindustrial.

b) Contribución a la seguridad sobre los pagos hechos a personas físicas prestadoras de servicio sin vínculo de empleo (autónomos), cobrada a las empresas y demás empleadores, con alícuota del $20 \%$ en genera ${ }^{88}$ sobre los pagos.

c) Contribución a la seguridad sobre pagos hechos a cooperativas de trabajo, cobrada a las empresas y demás personas que contraten dichas cooperativas, con alícuota del $15 \%{ }^{89}$ sobre el valor de los servicios contratados.

d) Contribución al "seguro accidente del trabajo" (SAT), cobrada a las empresas y demás empleadores, con alícuotas que varían entre el $0,5 \%$ y el $6 \%{ }^{90}$ sobre la hoja

\footnotetext{
${ }^{86} \mathrm{La}$ alícuota del 9\% es general y la alícuota del $15 \%$ es específica para instituciones financieras/bancos.

${ }^{87}$ Para las instituciones financieras/bancos la alícuota es del 22,5\%.

${ }^{88} \mathrm{Idem}$.

${ }^{89}$ En el caso de que los trabajadores de la cooperativa de trabajo presten servicios degradantes, o sea, que causen daños a la salud o integridad física y que dan derecho a la jubilación anticipada del trabajador, la alícuota de esa contribución del 15\% pasará al 20\%, 22\% o al 24\% dependiendo del tipo de trabajo.

${ }^{90}$ En el caso de que los trabajadores de la cooperativa de trabajo presten servicios degradantes, o sea, que causen daños a la salud o integridad física y que dan derecho a la jubilación anticipada del trabajador, la alícuota de la contribución al SAT recibe adicionales del 6\%, 9\% o el 12\% dependiendo del tipo de trabajo.
} 
de sueldos de los empleados, mediante cálculo para cada empresa, anualmente, conforme un factor atribuido por el Ministerio de la Seguridad Social con base en la cantidad de siniestros, gravedad y costos de atención a la salud del trabajador.

e) Contribución a la seguridad sobre los pagos hechos a los empleados los domésticos, cobrada de los empleadores domésticos, con alícuota del 12\% sobre la remuneración mensual pagada a los empleados.

f) Contribución del trabajador empleado (asegurado de la seguridad social), cobrada mediante descuento hecho por el empleador sobre su sueldo mensual, con alícuotas progresivas de acuerdo con el valor del sueldo: el 8\%, 9\% o el 11\%.

g) Contribución del trabajador autónomo (asegurado de la seguridad social), cobrada mediante descuento por el contratante persona jurídica/empresa (alícuota del 11\%) o pagada por el propio trabajador cuando contrata con persona física (alícuota del 20\%).

h) Para combatir el desempleo (reflejo de la crisis económica mundial), el Gobierno Federal está promoviendo temporalmente, para empresas de determinados sectores productivos más afectados con la crisis económica, una desgravación de la contribución a la seguridad sobre la hoja de sueldos de esas empresas, mediante la sustitución de la contribución del $20 \%$ sobre la hoja de sueldos, por una alícuota solo del $1 \%$ o el $2 \%$ sobre el rendimiento obtenido con las ventas y servicios.

\subsubsection{Contribución para los fondos de pensiones de los servidores públicos (artículo 40, CF)}

Los servidores públicos civiles del gobierno federal, de los estados, del DF y de las municipalidades disponen de regímenes legales propios de seguridad, diferenciados del régimen general de los trabajadores. Para financiar su régimen, el servidor público debe contribuir con una alícuota del $11 \%$ sobre su remuneración mensual. Los servidores inactivos/jubilados y los pensionados también necesitan pagar contribución a la seguridad, con alícuota del 11\%, pero sólo sobre el valor que reciben además de determinado límite mínimo/mensual. Los servidores públicos militares poseen un régimen de seguridad diferenciado.

\subsubsection{Contribuciones de intervención sobre el dominio económico (artículo 149 de la CF)}

El gobierno federal posee competencia para instituir, por medio de leyes, contribuciones para financiar medidas de intervención en sectores de la economía (dominio económico). Las contribuciones instituidas y en vigor actualmente son las siguientes:

a) CIDE combustibles (Ley No 10.336/2001), cobrada a las empresas del sector, con alícuotas variables conforme el combustible, y destinada a regular precios de venta, dar subsidios/incentivos, financiar el mantenimiento de autovías y la protección ambiental. 
b) CIDE royalties y tecnología (Ley No 10.168/2000), cobrada a personas jurídicas/empresas, con alícuota del 10\% sobre los valores pagados a residentes o viviendo en el extranjero en contratos de transferencia de tecnología o royalties, y destinada a financiar un fondo federal de promoción al desarrollo tecnológico.

c) CIDE cinema o CONDECINE (MP No 2.228-1/2001), cobrada a las empresas del sector, en valores fijados por período de tiempo o mediante alícuota del $11 \%$ en el caso de valores pagados a persona residente en el extranjero, es contribución destinada a financiar acciones de promoción del desarrollo de la industria cinematográfica nacional.

d) CIDE energía (Ley No 9.991/2000), cobrada a las empresas del sector energético, con alícuota del $0,5 \%$ sobre el rendimiento operacional neto de la actividad, es contribución destinada a fomentar acciones en pro del desarrollo energético brasileño.

e) CIDE sector marítimo (Ley No 10.893/2004), conocido como "adicional al flete para renovación de la marina mercante de Brasil” (AFRMM), cobrada con alícuotas variables sobre el valor del flete/transporte: el 10\% (cabotaje), el 25\% (largo curso) o el 40\% (fluvial y lacustre en las regiones norte y noreste de Brasil).

f) CIDE sector aeroportuario (Ley No 7.920/1989), conocida como "adicional de tarifa aeroportuaria" (ATAERO), es contribución cobrada de los usuarios y empresas de aviación con alícuota del $50 \%$ sobre el valor de las tarifas en los aeropuertos brasileños, y destinada a financiar mejorías y ampliaciones en la infraestructura aeroportuaria.

g) CIDE telecomunicaciones y universalización (Ley No 9.998/2000), conocida como "FUST", es cobrada a las empresas de telecomunicaciones, con alícuota del $1 \%$ sobre rendimiento operacional bruto de los servicios, y se destina al fondo de universalización/ampliación de la infraestructura de comunicaciones en Brasil.

h) CIDE telecomunicaciones y tecnología (Ley No 10.052/2000), conocida como "FUNTELL", es cobrada a las empresas del sector, con alícuota del 0,5\% sobre el rendimiento bruto de los servicios, y se destina al fondo de desarrollo de tecnología del sector.

i) CIDE INCRA (Decreto-Ley No 1.146/1970), es cobrada a las empresas empleadoras en general, con alícuota del 0,2\% sobre la hoja de sueldos pagados a los empleados, y se destina al Instituto Nacional de Colonización y Reforma Agraria.

j) CIDE SEBRAE-APEX-ABDI (Ley No 8.029/1990), es una contribución cobrada a las empresas empleadoras en general, con alícuota del $0,3 \%$ sobre la hoja de sueldos pagados a los empleados, y se destina al financiamiento de los programas y acciones de apoyo a los empresarios brasileños, realizados por el Servicio Brasileño de Apoyo a la Micro y Pequeña Empresa (SEBRAE), por la Agencia de Apoyo a las Exportaciones de Brasil (APEX) y por la Agencia Brasileña de Desarrollo Industrial (ABDI). 


\subsubsection{Contribuciones de interés de categorías profesionales o económicas}

Estas contribuciones son tributos cuyo hecho generador, al contrario de las demás contribuciones antes tratadas, no es una manifestación de riqueza, sino el hecho de una persona física o jurídica pertenecer a una categoría profesional o económica. Existen dos tipos básicos de contribuciones de interés de categorías, sean ellas profesionales o económicas: i) contribuciones sindicales; y ii) contribuciones corporativas.

\subsubsection{Contribuciones sindicales}

Los sindicatos que representan trabajadores y empleadores en Brasil son financiados por diversas contribuciones, y entre ellas hay una contribución tributaria: la contribución sindical anual, prevista en el Decreto-Ley No 5.452/1943 (sindicatos urbanos) y en el Decreto-Ley No 1.166/1971 (sindicatos rurales). Para los sindicatos de los trabajadores empleados, la contribución es un valor fijo equivalente a un día de sueldo del mes de marzo de cada año; y para los trabajadores autónomos es un pequeño valor fijo anual. Ya para financiar los sindicatos que representan las empresas y empleadores en general, la contribución está calculada y pagada en enero de cada año y su valor se calcula mediante aplicación de alícuotas del 0,8\% al 0,02\% sobre el valor del capital social registrado de las sociedades empresariales. Y para los productores rurales personas físicas, la contribución se cobra con alícuotas del $0,8 \%$ al $0,02 \%$ sobre el valor de la tierra/propiedad rural explotada ${ }^{91}$.

\subsubsection{Contribuciones corporativas}

Son contribuciones que financian las autarquías (personas jurídicas gubernamentales) que fiscalizan el ejercicio de profesiones reglamentadas por ley, y son debidas anualmente (por eso son llamadas de "anualidades profesionales") en valores fijados por profesional registrado. Abogados, médicos, ingenieros, contables y diversos otros profesionales deben pagar la contribución todos los años, además de las sociedades formadas por ellos. El valor es regional, basado en los costos de las entidades, variando mucho entre los estados brasileños. Sólo para que se tenga una idea, el valor medio pagado por un abogado brasileño suscrito en algunos de los estados más desarrollados (sur y sureste) es de aproximadamente US\$ 350,0092 al año.

\footnotetext{
${ }^{91}$ Petry, Rodrigo Caramori (2013b). "Contribuição sindical patronal rural (CNA): aspectos polêmicos". Revista de Estudos Tributários, No 90, marzo-abril, Porto Alegre: IOB e IET, pp. 81-85.

${ }^{92} \mathrm{El}$ dólar norteamericano aquí sirve sólo como una referencia didáctica y está estimado en el cambio de R\$ 2,00 para US\$1,00 (junio/2013).
} 


\subsection{Contribución para el costeo del servicio \\ de iluminación pública (artículo 149-A, CF)}

Para costear los gastos de los municipios y del DF con el servicio de iluminación pública, la Constitución autoriza la institución y cobranza, por medio de ley municipal o distrital, de contribución tributaria con esa finalidad. Por tanto, cada uno de los 5.570 municipios además del distrito federal, puede cobrar ese tributo, y muchos lo hacen, generalmente por medio del establecimiento de un pequeño valor mensual por inmueble, pudiendo ese tributo venir destacado en la cuenta de cobranza por la energía consumida en el inmueble ${ }^{93}$.

\section{REGÍMENES SIMPLIFICADOS DE TRIBUTACIÓN PARA PEQUEŃOS NEGOCIOS EN BRASIL}

Con base en los artículos 170, IX, y 179 de la Constitución brasileña, el gobierno federal, estados, DF y municipalidades deben instituir regímenes específicos de tributación para las micro y pequeñas empresas, con carga tributaria más baja y forma de cálculo más simple y menos onerosa, como forma de estímulo para el desarrollo de las empresas. El régimen simplificado más amplio que existe es el llamado "SIMPLE Nacional”, previsto en la Ley Complementaria No 123/2006. El SIMPLE autoriza a las empresas que obtengan rendimiento bruto anual de hasta US\$1.800.000,00 a calcular los principales tributos de forma unificada y con carga tributaria menor, mediante aplicación de una alícuota (\%) sobre el rendimiento bruto de las ventas y servicios, mes a mes. ${ }^{94}$ Las microempresas o empresas de pequeño porte que posean socio viviendo en el extranjero, o que participen en el capital de otra empresa o que tengan como socio una empresa, entre otros casos, no pueden beneficiarse del régimen SIMPLE.

Debido a nuestras limitaciones de espacio, no presentaremos las alícuotas aplicables a las micro y pequeñas empresas en el régimen SIMPLE, teniendo en cuenta que, a pesar de que más del 95\% de las empresas de Brasil tiene micro o pequeño porte, más del $90 \%$ de la recaudación tributaria se obtiene con las recaudaciones hechos por las medianas y grandes empresas, que no siguen el régimen SIMPLE, estando, por el contrario, sometidas a los regímenes comunes de tributación ya presentados en este estudio.

Existe un régimen tributario todavía más simplificado y favorecido para el caso del microempresario individual, el "MEI" (LC No 128/2008), o sea, aquella persona física que dirige el propio negocio y obtiene hasta US\$ 30.000,00 al año

\footnotetext{
${ }^{93}$ En el municipio de São Paulo (Ley No 13.479/2002), el valor está cerca de aproximadamente US\$2,00 por inmueble residencial y de US\$ 6,00 por inmueble no residencial (empresas de comercio, etc.).

${ }^{94}$ Incluida aquí, como empresa que puede beneficiarse del SIMPLE, la persona física emprendedora de pequeño porte, sin socios, pero que asume la forma jurídica de empresario individual de responsabilidad limitada, también conocido como "EIRELI" (Ley No 12.441/2011).
} 
(incluye peluqueras, pintores y electricistas domésticos, comerciantes de calle, etc.). En el MEI los tributos debidos son solo tres, en valores fijos mensuales: US\$15,00 como contribución a la seguridad social, y US\$ 0,50 más como impuesto de los estados sobre circulación de mercancías o US\$2,50 a título de impuesto municipal sobre servicios.

\section{RÉGIMEN ESPECIAL DE INCENTIVO TRIBUTARIO REGIONAL: La Zona Franca de Manaus}

En Brasil es históricamente común el uso de incentivos tributarios para incentivar el desarrollo económico, industrial y tecnológico de regiones del país menos desarrolladas, como el norte y noreste. Uno de los más conocidos regímenes de incentivo regional, que atrae inversores y empresas brasileñas y de otros países, es el régimen de desgravación de tributos (exenciones, alícuotas $0 \%$, etc.) en las operaciones de empresas instaladas en la llamada Zona Franca de Manaus (artículo 40 del ADCT de la Constitución), región que ocupa el Municipio de Manaus, capital del Estado del Amazonas, estado donde se localiza gran parte de la Selva Amazónica.

\section{OTROS ASPECTOS INTERESANTES SOBRE EL SISTEMA TRIBUTARIO BRASILEÑO}

Brasil posee una de las más altas cargas tributarias del mundo (actualmente cerca del $36 \%$ del $\mathrm{PIB}^{95}$ ), pero los servicios públicos todavía necesitan muchas mejorías, y la población en general no se ve satisfecha con la cobranza de los tributos, por juzgarla desproporcionada. La alta carga tributaria perjudica la actividad económica, e induce a muchos contribuyentes al no pago, lo que fuerza el Poder Legislativo y el gobierno a instituir, por medio de leyes propias, programas especiales de cuotas de débitos tributarios, aplicando descuentos/perdones de parte de las multas e intereses.

Además, los contribuyentes brasileños están sujetos a una amplia cantidad de obligaciones documentales, o sea, están obligados a rellenar y entregar un sinfín de formularios y declaraciones, por medio de los cuales declaran sus negocios al Fisco.

Por medio de las declaraciones y formularios entregados por los contribuyentes y también por otras personas que negocian con contribuyentes $(v$. gr. bancos, clientes, proveedores, notarios de registro de inmuebles, etc.), el gobierno brasileño (Uno, Estados, DF y municipalidades) realiza diversas fiscalizaciones, en su mayor parte por medio electrónico, pero también por medio de diligencias físicas en los establecimientos de los contribuyentes empresarios. El principal órgano fiscal

\footnotetext{
${ }_{95}$ PIB (Producto Interno Bruto) es producto de una encuesta estadística que busca medir la suma de las riquezas producidas en el país durante un ejercicio financiero (1 de enero al 31 de diciembre).
} 
brasileño (Secretaría de Hacienda Federal de Brasil) posee y desarrolla diversos sistemas informatizados de control fiscal, que son considerados algunos de los más sofisticados y perfeccionados del mundo.

\section{CONCLUSiOnes}

Como fue posible observar en el presente artículo, el sistema constitucional tributario brasileño es bastante complejo, formando un régimen de especial protección a los ciudadanos-contribuyentes, diferente de muchos otros países, que poseen pocos dispositivos expresados sobre materia tributaria.

Los primeros límites a la potestad tributaria en Brasil están presentes en las propias normas que autorizan a la institución de los tributos, pues la Constitución brasileña delimita expresamente cuáles especies de tributo pueden ser creados, y cuáles son sus características básicas: impuestos, tasas, contribuciones de mejora, préstamos obligatorios y contribuciones especiales, distribuyendo los diversos tributos entre las esferas de poder (Unión Federal, Estados, Distrito Federal y Municipios), para garantizarles la autonomía financiera y así garantizar autonomía política.

Ese complejo sistema de repartición de potestades tributarias funciona al lado de un sistema de repartición de ingresos recaudados entre el gobierno federal (unión), los estados, el distrito federal y los municipios.

Al lado de las normas de poder tributario, el sistema de limitaciones al poder de tributar en Brasil también posee diversas hipótesis expresadas, de inmunidad a los tributos, apartando de la tributación ciertos hechos, actividades, bienes o personas.

Además de eso, la Constitución Federal de 1988 posee un abundante rol de derechos fundamentales aplicables a la tributación, que deben ser aplicados en conjunto con diversos principios tributarios, expresados o implícitos, y que se dividen básicamente en: principios tributarios (legalidad, anterioridad de la ley, irretroactividad de la ley, isonomía, capacidad contributiva, prohibición de confisco, y protección al régimen federativo) y sus reglas técnicas de aplicación (no acumulación, selectividad, y progresividad fiscal); y principios económico-tributarios (protección del orden económico).

Para la debida aplicación de los principios y reglas, aun son identificados, implícitamente, postulados de aplicación (razonabilidad, proporcionalidad y prohibición de exceso), muy importantes en materia tributaria. La Constitución brasileña aún posee una serie de otros límites al poder de tributar, que en el presente artículo fueron identificados como "reglas de otra naturaleza", por no encajarse en una clasificación más precisa.

En la segunda parte de la presentación del sistema tributario brasileño, el presente texto abordó los diversos tributos existentes, identificando que Brasil tributa fuertemente las importaciones (impuesto de importación, IPI, ICMS, PIS, COFINS y tasas) y el consumo interno (con impuestos IPI, ICMS, ISS, 
contribuciones PIS y COFINS, y contribuciones de intervención), tributando en menor intensidad la propiedad y la renta.

La carga tributaria en Brasil es concentrada en los impuestos y en las contribuciones especiales, esas con especial destaque, pues poseen amplio campo de incidencia, incidiendo sobre el sistema de nómina y pagos, el lucro de las empresas, la facturación de ventas/servicios, el ingreso de las empresas y las importaciones. Además de eso, aún hay espacio para la creación de nuevos impuestos y sobre todo contribuciones, a ser creados por el legislador federal, al cual le restó el poder residual en materia tributaria.

El sistema tributario brasileño, aunque claramente definido en la Constitución, es uno de los sistemas más complejos en el mundo, teniendo en cuenta la enorme cantidad de impuestos, tasas y contribuciones, con los más diversos regímenes jurídicos, repartidos entre las distintas esferas de poder (federal, estatal y de las municipalidades).

La complejidad de la legislación y la alta carga tributaria y documental acaban por generar litigios en masa involucrando disputas entre el Fisco y los contribuyentes. Las divergencias de entendimiento entre los tribunales brasileños y la falta de claridad del sistema acaban muchas veces generando cierta inseguridad en los inversores extranjeros ${ }^{96}$. Por todos esos motivos en Brasil hay un constante debate entre contribuyentes, gobierno, legisladores y estudiosos, con el propósito de realización de reformas en la Constitución y en las leyes para simplificar y perfeccionar el sistema jurídico tributario. El objetivo es garantizar la gobernabilidad al mismo tiempo en que se atraen inversiones, crecimiento, generación de empleo, renta y justicia fiscal.

\section{BiBLIOGRAFÍA CITADA}

Amorim, Diego (2012). "Moradores do DF são os que mais pagam impostos em todo o Brasil." Correio Braziliense. Brasília/DF: Correio Braziliense. Disponible en: <http://www.correiobraziliense.com.br/app/noticia/cidades/2012/09/01/ interna_cidadesdf,320303/moradores-do-df-sao-os-que-mais-pagam-impostos-em-todo-o-brasil.shtml> [Consulta: 14 junio 2013].

ÁvILA, Humberto (2009). Teoria dos princípios: da definição à aplicação dos princípios jurídicos. São Paulo: Malheiros, 9a edição, 190 pp.

BotTALo, Eduardo Domingos (2009). IPI: princípios e estrutura. São Paulo: Dialética, $207 \mathrm{pp}$.

Secretaria da Receita Federal do Brasil (2012). Carga Tributária no Brasil 2011. Brasília: Ministério da Fazenda, noviembre 2012. Disponible en: <http://www.

${ }_{96}$ Petry, Rodrigo Caramori (2004b). "Apontamentos sobre a problemática da tributação no Brasil”. Revista Tributária e de Finanças Públicas, No 59, São Paulo: Revista dos Tribunais, noviembre-diciembre, pp. 41-59. 
receita.fazenda.gov.br/Publico/estudoTributarios/estatisticas/CTB2011.pdf>. [Consulta: 14 abril 2013].

Ministério do Desenvolvimento, Indústria e Comércio Exterior (2013). Página oficial do MDIC. Brasília. Disponible en: <http://www.desenvolvimento.gov. br/sitio/> [Consulta: 21 abril 2013].

Ministério das Relaçōes Exteriores (2013). Página brasileira do Mercosul. Brasília/ DF. Disponible en: <http://www.mercosul.gov.br>. [Consulta: 21 abril 2013].

IPEA (Instituto de Pesquisa Econômica Aplicada) (2009). Política fiscal e justiça social no Brasil: o caso do IPTU. Disponible en: <http://caderno.allanpatrick. net/wp-content/uploads/2009/08/ipea-comunicado-presidencia-28-iptu-27-08-2009.pdf> [Consulta: 13 junio 2013].

IPEA (Instituto de Pesquisa Econômica Aplicada) (2011). "O uso dos instrumentos de financiamento para a política urbana no Brasil”. Comunicados IPEA, No 112, Brasília: IPEA, 20 septiembre de 2011. Disponible en: <http://www.ipea.gov. br/portal/images/stories/PDFs/comunicado/110920_comunicadoipea1 12. pdf> [Consulta: 13 junio 2013].

Petry, Rodrigo Caramori (2004a). "As contribuições especiais ao longo das Constituições brasileiras: um tributo sui generis". Revista de Estudos Tributários, № 40, noviembre-deciembre, Porto Alegre: Síntese e IET, pp. 137-160.

Petry, Rodrigo Caramori (2004b). "Apontamentos sobre a problemática da tributação no Brasil”. Revista Tributária e de Finanças Públicas, No 59, São Paulo: Revista dos Tribunais, noviembre-diciembre, pp. 41-59.

Petry, Rodrigo Caramori (2009a). "O princípio da anterioridade da lei tributária: teoria geral e análise de casos”. Revista Dialética de Direito Tributário, No 170, São Paulo: Dialética, pp. 75-92.

Petry, Rodrigo Caramori (2009b). Contribuições ao PIS/Pasep e Cofins. São Paulo: Dialética, 646 pp.

Petry, Rodrigo Caramori (2010). "Reflexões sobre a estrutura do direito tributário no Brasil”. Revista Direito Tributário Atual, No 24, São Paulo: Dialética e Instituto Brasileiro de Direito Tributário (IBDT), pp. 495-542.

Petry, Rodrigo Caramori (2011). "O passado, o presente e o futuro da tributação sobre a movimentação financeira no Brasil: IPMF, CPMF e CSS”. Revista Tributária e de Finanças Públicas, No 99, São Paulo: Revista dos Tribunais, julio-agosto, pp. 225-234.

Petry, Rodrigo Caramori (2013a). "Análise jurídica da carga tributária brasileira”. Revista de Estudos Tributários, No 93, São Paulo: IOB/Síntese e Instituto de Estudos Tributários (IET), septiembre-octubre/2013, pp. 81-117.

PETRY, Rodrigo Caramori (2013b). "Contribuição sindical patronal rural (CNA): aspectos polêmicos”. Revista de Estudos Tributários, No 90, marzo-abril, Porto Alegre: IOB e IET, pp. 81-99. 
Petry, Rodrigo Caramori (2014). "Direito constitucional tributário comparado: A tributação nas Constituiçõoes do Brasil e de outros países”. Revista Direito Tributário Atual, No 30, São Paulo: Dialética e Instituto Brasileiro de Direito Tributário (IBDT), pp. 351-385.

Sebrae, Dieese e IbGe (2013). Empreendedorismo hoje: mapa das micro e pequenas empresas. Disponible en: <http://www.brasil.gov.br/empreendedor/empreendedorismo-hoje/o-mapa-das-micro-e-pequenas-empresas> [Consulta: 14 junio 2013].

\section{NORMAS CITADAS}

Código Tributário Brasileiro (Lei No 5.172/1966), Brasília/DF: Congresso Nacional. Disponible en: <http://www.planalto.gov.br/ccivil_03/leis/15172.htm>.

Constituição (1988), Brasília/DF: Congresso Nacional, 5 de octubre de 1988. Disponible en: <http://www.planalto.gov.br/ccivil_03/constituicao/constituicao.htm>.

Decreto-Lei No 5.452/1943. Brasília/DF: Presidência da República. Disponible en: <http://www.planalto.gov.br/ccivil_03/decreto-lei/del5452.htm >.

Decreto-Lei No 34/1966. Brasília/DF: Presidência da República. Disponible en: <http://www.planalto.gov.br/ccivil_03/decreto-lei/1965-1988/Del0034.htm>.

Decreto-Lei No 37/1966. Brasília/DF: Presidência da República. Disponible en: <http://www.planalto.gov.br/ccivil_03/decreto-lei/del0037.htm>.

Decreto-Lei No 57/1966. Brasília/DF: Presidência da República. Disponible en: <http://www.planalto.gov.br/ccivil_03/decreto-lei/del0057.htm >.

Decreto-Lei No 406/1968. Brasília/DF: Presidência da República. Disponible en: <http:/www.planalto.gov.br/ccivil_03/decreto-lei/del0406.htm>.

Decreto-Lei No 1.146/1970. Brasília/DF: Presidência da República. Disponible en: <http://www.planalto.gov.br/ccivil_03/decreto-lei/1965-1988/Del1146.htm >.

Decreto-Lei No 1.166/1971. Brasília/DF: Presidência da República. Disponible en: <http://www.planalto.gov.br/ccivil_03/decreto-lei/1965-1988/Del1166.htm >.

Decreto-Lei No 1.199/1971. Brasília/DF: Presidência da República. Disponible en: <http://www.planalto.gov.br/ccivil_03/decreto-lei/del1199.htm>.

Decreto-Lei No 1.578/1977. Brasília/DF: Presidência da República. Disponible en: <http://www.planalto.gov.br/ccivil_03/decreto-lei/del1578.htm>.

Decreto-Lei No 1.783/1980. Brasília/DF: Presidência da República. Disponible en: <http://www.planalto.gov.br/ccivil_03/decreto-lei/del1783.htm>.

Decreto-Lei No 2.471/1988. Brasília/DF: Presidência da República. Disponible en: <http://www.planalto.gov.br/ccivil_03/decreto-lei/Del2471.htm>.

Decreto No 3.000/1999. Brasília/DF: Presidência da República. Disponible en: <http://www.planalto.gov.br/ccivil_03/decreto/d3000.htm>. 
Decreto Estadual No 45.490/2000. São Paulo/Estado de São Paulo: Poder Executivo Estadual. Disponible en: <http://www.al.sp.gov.br/legislacao/norma. do? id $=5072>$.

Decreto No 4.382/2002. Brasília/DF: Presidência da República. Disponible en: <http://www.planalto.gov.br/ccivil_03/decreto/2002/D4382.htm>.

Decreto No 4.383/2002 (internaliza o Acordo de Complementação Econômica No 53/2002 entre o Brasil e o México). Brasília/DF: Presidência da República. Disponible en: <http://www.planalto.gov.br/ccivil_03/decreto/2002/D4383. htm>.

Decreto Estadual No 46.655/2002. São Paulo/Estado de São Paulo: Poder Executivo Estadual. Disponible en: <http://www.fazenda.sp.gov.br/itcmd/decreto_46655.asp>.

Decreto No 6.000/2003. Brasília/DF: Presidência da República. Disponible en: <http://www.planalto.gov.br/ccivil_03/_Ato2004-2006/2006/Decreto/ D6000.htm>.

Decreto Legislativo No 1.012/2005. Brasília/DF: Congresso Nacional. Disponible en: <http://www2.camara.leg.br/legin/fed/decleg/2005/decretolegislativo1012-27-outubro-2005-539059-convencao-quadro-36837-pl.html>.

Decreto No 5.658/2006. Brasília/DF: Presidência da República. Disponible en: <http://www.planalto.gov.br/ccivil_03/_Ato2004-2006/2006/Decreto/ D5658.htm>.

Decreto No 6.306/2007. Brasília/DF: Presidência da República. Disponible en: <http:/www.planalto.gov.br/ccivil_03/_Ato2007-2010/2007/Decreto/ D6306.htm>.

Decreto No 6.759/2009. Brasília/DF: Presidência da República. Disponible en: <http://www.planalto.gov.br/ccivil_03/_ato2007-2010/2009/decreto/d6759. htm>.

Decreto No 7.212/2010. Brasília/DF: Presidência da República. Disponible en: <http://www.planalto.gov.br/ccivil_03/_ato2007-2010/2010/decreto/d7212. htm>.

Decreto No 7.555/2011. Brasília/DF: Presidência da República. Disponible en: <http://www.planalto.gov.br/ccivil_03/_ato2011-2014/2011/Decreto/D7555. htm>.

Decreto No 7.660/2011. Brasília/DF: Presidência da República. Disponible en: $<$ http://www.planalto.gov.br/ccivil_03/_ato2011-2014/2011/decreto/d7660. htm>.

Lei No 4.502/1964. Brasília/DF: Congresso Nacional. Disponible en: <http:// www.planalto.gov.br/ccivil_03/leis/14502.htm>.

Lei No 5.143/1966. Brasília/DF: Congresso Nacional. Disponible en: <http:// www.planalto.gov.br/ccivil_03/leis/L5143.htm>. 
Lei No 5.868/1972. Brasília/DF: Congresso Nacional. Disponible en: <http:// www.planalto.gov.br/ccivil_03/leis/15868.htm>.

Lei No 6.194/1974. Brasília/DF: Congresso Nacional. Disponible en: <http:// www.planalto.gov.br/ccivil_03/Leis/16194.htm>.

Lei Estadual No 6.374/1989. São Paulo/Estado de São Paulo: Assembléia Legislativa. Disponible en: <http://governo-sp.jusbrasil.com.br/legislacao/187048/ lei-6374-89>.

Lei No 7.766/1989. Brasília/DF: Congresso Nacional. Disponible en: <http:// www.planalto.gov.br/ccivil_03/leis/17766.htm >.

Lei No 7.920/1989. Brasília/DF: Congresso Nacional. Disponible en: <http:// www.planalto.gov.br/ccivil_03/Leis/L7920.htm >.

Lei No 8.029/1990. Brasília/DF: Congresso Nacional. Disponible en: <http:// www.planalto.gov.br/ccivil_03/leis/L8029cons.htm >.

Lei No 8.212/1991. Brasília/DF: Congresso Nacional. Disponible en: <http:// www.planalto.gov.br/ccivil_03/leis/l8212cons.htm>.

Lei No 8.894/1994. Brasília/DF: Congresso Nacional. Disponible en: <http:// www.planalto.gov.br/ccivil_03/leis/18894.htm >.

Lei Complementar No 87/1996. Brasília/DF: Congresso Nacional. Disponible en: <http://www.planalto.gov.br/ccivil_03/leis/lcp/lcp87.htm>.

Lei No 9.393/1996. Brasília/DF: Congresso Nacional. Disponible en: <http:// www.planalto.gov.br/ccivil_03/leis/l9393.htm>.

Lei No 9.532/1997. Brasília/DF: Congresso Nacional. Disponible en: <http:// www.planalto.gov.br/ccivil_03/leis/l9532.htm>.

Lei No 9.991/2000. Brasília/DF: Congresso Nacional. Disponible en: <http:// www.planalto.gov.br/ccivil_03/leis/19991.htm >.

Lei No 9.998/2000. Brasília/DF: Congresso Nacional. Disponible en: <http:// www.planalto.gov.br/ccivil_03/leis/19998.htm >.

Lei No 10.052/2000. Brasília/DF: Congresso Nacional. Disponible en: <http:// www.planalto.gov.br/ccivil_03/leis/110052.htm >.

Lei No 10.168/2000. Brasília/DF: Congresso Nacional. Disponible en: <http:// www.planalto.gov.br/ccivil_03/leis/l10168.htm >.

Lei Estadual No 10.705/2000. São Paulo/Estado de São Paulo: Assembléia Legislativa. Disponible en: <http://www.fazenda.sp.gov.br/itcmd/ LEI_10705consolidada.asp >.

Lei No 10.257/2001. Brasília/DF: Congresso Nacional. Disponible en: <http:// www.planalto.gov.br/ccivil_03/leis/leis_2001/110257.htm>.

Lei No 10.336/2001. Brasília/DF: Congresso Nacional. Disponible en: <http:// www.planalto.gov.br/ccivil_03/leis/leis_2001/110336.htm >.

Lei Municipal No 13.479/2002. Município de São Paulo/Estado de São Paulo: Câmara de Vereadores. Disponible en: <http://ww2.prefeitura.sp.gov.br/arquivos/secretarias/financas/legislacao/Lei-13479-2002.pdf>. 
Lei Complementar No 116/2003. Brasília/DF: Congresso Nacional. Disponible en: <http://www.planalto.gov.br/ccivil_03/leis/lcp/lcp116.htm>.

Lei No 10.893/2004. Brasília/DF: Congresso Nacional. Disponible en: <http:// www.planalto.gov.br/ccivil_03/_ato2004-2006/2004/lei/110.893.htm >.

Lei Estadual No 13.136/2004. Florianópolis/Estado de Santa Catarina. Assembléia Legislativa. Disponible en: <http://legislacao.sef.sc.gov.br/html/leis/2004/ lei_04_13136.htm>.

Lei Complementar No 123/2006. Brasília/DF: Congresso Nacional. Disponible en: <http://www.planalto.gov.br/ccivil_03/leis/lcp/lcp123.htm>.

Lei No 11.441/2007. Brasília/DF: Congresso Nacional. Disponible en: <http:// www.planalto.gov.br/ccivil_03/_ato2007-2010/2007/lei/111441.htm>.

Lei Complementar No 128/2008. Brasília/DF: Congresso Nacional. Disponible en: <http://www.planalto.gov.br/ccivil_03/leis/lcp/lcp128.htm>.

Lei Estadual No 13.296/2008. São Paulo/Estado de São Paulo: Assembléia Legislativa. Disponible en: <http://www.al.sp.gov.br/repositorio/legislacao/lei/2008/ lei\%20n.13.296,\%20de\%2023.12.2008.htm>.

Lei No 12.546/2011. Brasília/DF: Congresso Nacional. Disponible en: <http:// www.planalto.gov.br/ccivil_03/_ato2011-2014/2011/lei/112546.htm>.

Lei No 12.741/2012. Brasília/DF: Congresso Nacional. Disponible en: <http:// www.planalto.gov.br/ccivil_03/_Ato2011-2014/2012/Lei/L12741.htm>.

Lei No 12.814/2013. Brasília/DF: Congresso Nacional. Disponible en: <http:// www.planalto.gov.br/ccivil_03/_Ato2011-2014/2013/Lei/L12814.htm>.

Resolução do Senado Federal No 313/1983. Brasília/DF: Senado Federal. Disponible en: <http://legis.senado.gov.br/legislacao/ListaPublicacoes. action?id=12 8215\&tipoDocumento $=$ RSF\&tipoTexto $=\mathrm{PUB}>$.

Resolução do Senado Federal No 95/1986. Brasília/DF: Senado Federal. Disponible en: <http://www.senado.gov.br/publicacoes/anais/pdf/Resolucoes/1989.pdf>.

Resolução do Senado Federal No 22/1989. Brasília/DF: Senado Federal. Disponible en: <http://www.senado.gov.br/publicacoes/anais/pdf/Resolucoes/1989.pdf>.

Resolução do Senado Federal No 9/1992. Brasília/DF: Senado Federal. Disponible en: <http://legis.senado.gov.br/legislacao/ListaPublicacoes.action?id=136383>.

Resolução do Senado Federal No 13/2012. Brasília/DF: Senado Federal. Disponible en: <http://legis.senado.gov.br/legislacao/ListaPublicacoes.action?id=264825>.

\section{JURISPRUDENCIA BRASILEÑA CITADA}

Superior Tribunal de Justiça (STJ). 2a Turma. REsp No 16.951/SP, Relator Ministro Adhemar Maciel, j. em 05 de diciembre de 1996. Disponible en: <http://stj.jusbrasil.com.br/jurisprudencia/536021/recurso-especial-resp16951-sp-1991-0024450-3>. 
Supremo Tribunal Federal (STF). Pleno. ADI No 1.600, Relator Ministro Sidney Sanches/Relator para acórdão Ministro Nelson Jobim, j. em 26 de noviembre de 2001. Disponible en: <http://www.stf.jus.br/portal/jurisprudencia/listarJurisprudencia.asp?s1=\%28ADI\%24\%2ESCLA $\% 2 \mathrm{E}+\mathrm{E}+1600 \% 2 \mathrm{ENUME} \% 2$ $\mathrm{E} \% 29+\mathrm{OU}+\% 28 \mathrm{ADI} \% 2 \mathrm{EACMS} \% 2 \mathrm{E}+\mathrm{ADJ} 2+1600 \% 2 \mathrm{EACMS} \% 2 \mathrm{E} \% 29 \&$ base=baseAcordaos\&url=http://tinyurl.com/clctqta $>$.

Supremo Tribunal Federal (STF). Pleno. RE No 562.045/RS RG, Relator Ministro Ricardo Lewandowski, j. em 1 de febrero de 2008. Disponible en: <http:// www.stf.jus.br/portal/jurisprudencia/listarJurisprudencia.asp?s $1=\% 28 \mathrm{RE} \%$ 24\%2ESCLA $\% 2 \mathrm{E}+\mathrm{E}+562045 \% 2 \mathrm{ENUME} \% 2 \mathrm{E} \% 29+\mathrm{OU}+\% 28 \mathrm{RE} \% 2 \mathrm{EPR}$ $\mathrm{CR} \% 2 \mathrm{E}+\mathrm{ADJ} 2+562045 \% 2 \mathrm{EPRCR} \% 2 \mathrm{E} \% 29 \&$ base=baseRepercussao\&url= http://tinyurl.com/acyfaah>.

Supremo Tribunal Federal (STF). $1^{\text {a }}$ Turma. Ag.Reg. RE No 550.170/SP, Relator Ministro Ricardo Lewandowski, j. em 7 de junio de 2011. Disponible en: <http://www.stf.jus.br/portal/jurisprudencia/listarJurisprudencia.asp?s1=\% 28RE\% 24\%2ESCLA\%2E+E+550170\%2ENUME\%2E\%29+OU+\%28RE $\% 2 \mathrm{EACMS} \% 2 \mathrm{E}+\mathrm{ADJ} 2+550170 \% 2 \mathrm{EACMS} \% 2 \mathrm{E} \% 29 \&$ base=baseAcordaos \&url=http://tinyurl.com/a92s36h>.

Supremo Tribunal Federal (STF). Pleno. RE No 723.651/RS, Relator Ministro Marco Aurélio, j. em 11 de abril de 2013. Disponible en: <http://www.stf. jus.br/portal/jurisprudencia/listarJurisprudencia.asp?s1=\%28RE\%24\%2ES CLA\%2E+E+723651\%2ENUME\%2E\%29+OU+\%28RE\%2EPRCR\%2E +ADJ2+723651\%2EPRCR\%2E\%29\&base=baseRepercussao\&url=http:// tinyurl.com/d8ebx6j>. 